\title{
REMOTE DETECTION OF INTERNAL PIPELINE CORROSION USING FLUIDIZED SENSORS
}

\author{
FINAL REPORT \\ SwRI ${ }^{\circledR}$ Project 18.10926 \\ NETL Project 42267 \\ Prepared for \\ U.S. Department of Energy \\ National Energy Technology Laboratory
}

Prepared by

Narasi Sridhar and Garth Tormoen

Southwest Research Institute ${ }^{\circledR}$

6220 Culebra Road

San Antonio, TX 78228

Ashok Sabata

Aginova, Inc.

3 Chambry Court

Freehold, NJ 07728

October 31, 2005

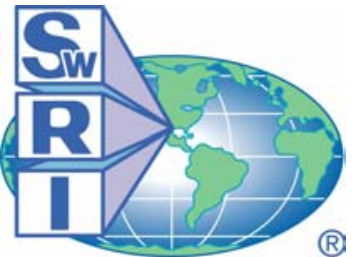

SOUTHWEST RESEARCH IN STITUTE 


\title{
REMOTE DETECTION OF INTERNAL PIPELINE CORROSION USING FLUIDIZED SENSORS
}

\author{
FINAL REPORT \\ SwRI ${ }^{\circledR}$ Project 18.10926 \\ NETL Project 42267 \\ Prepared for \\ U.S. Department of Energy \\ National Energy Technology Laboratory
}

Prepared by

Narasi Sridhar and Garth Tormoen

Southwest Research Institute ${ }^{\circledR}$

6220 Culebra Road

San Antonio, TX 78228

Ashok Sabata

Aginova, Inc.

3 Chambry Court

Freehold, NJ 07728

October 31, 2005

APPROVED:

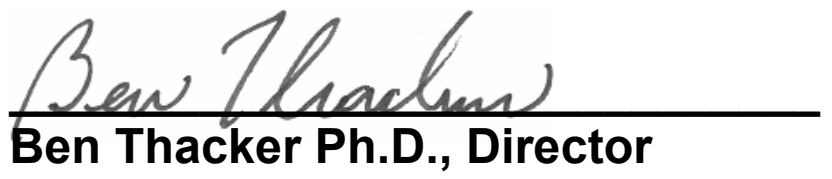

Materials Engineering Department 


\section{ACKNOWLEDGMENTS}

The authors acknowledge the important technical contributions made by Dr. Sean Brossia (currently at CC Technologies) who initiated the project and accomplished many of the early results in the project. The authors are also grateful for the assistance of Roger Dykstra and Albert Faz in assembling and performing the tests. Andre Barajas (SwRI) performed the sensor flow calculations. Drs. Drela and Epstein, Massachusetts Institute of Technology, performed the wind tunnel tests for power generation assessment. The project was funded by the National Energy Technology Laboratories of the Department of Energy and Pipeline Research Council International (through Kiefner \& Associates). The support of Laurie Perry and Harvey Haines is gratefully acknowledged.

\section{DISCLAIMER}

This report was prepared as an account of work sponsored by an agency of the United States Government. Neither the United States government nor any agency thereof, nor any of their employees, makes any warranty, express or implied, or assumes any legal liability or responsibility for the accuracy, completeness, or usefulness of any information, apparatus, product, or process disclosed, or represents that its use would not infringe privately owned rights. Reference herein to any specific commercial product, process, or service by trade name, trademark, manufacturer, or otherwise does not necessarily constitute or imply its endorsement, recommendation, or favoring by the United States Government or any agency thereof. The views and the opinions of authors expressed herein do not necessarily state or reflect those of the United States Government or any agency thereof. 


\section{EXECUTIVE SUMMARY}

Pipelines present a unique challenge to monitoring because of the great geographical distances they cover, their burial depth, their age, and the need to keep the product flowing without much interruption. Most other engineering structures that require monitoring do not pose such combined challenges. In this regard, a pipeline system can be considered analogous to the blood vessels in the human body. The human body has an extensive "pipeline" through which blood and other fluids are transported. The brain can generally sense damage to the system at any location and alert the body to provide temporary repair, unless the damage is severe. This is accomplished through a vast network of fixed and floating sensors combined with a vast and extremely complex communication/decision making system. The project described in this report mimics the distributed sensor system of our body, albeit in a much more rudimentary fashion.

Internal corrosion is an important factor in pipeline integrity management. At present, the methods to assess internal corrosion in pipelines all have certain limitations. In-line inspection tools are costly and cannot be used in all pipelines. Because there is a significant time interval between inspections, any impact due to upsets in pipeline operations can be missed. Internal Corrosion Direct Assessment (ICDA) is a procedure that can be used to identify locations of possible internal corrosion. However, the uncertainties in the procedure require excavation and location of damage using more detailed inspection tools. Non-intrusive monitoring techniques can be used to monitor internal corrosion, but these tools also require pipeline excavation and are limited in the spatial extent of corrosion they can examine. Therefore, a floating sensor system that can deposit at locations of water accumulation and communicate the corrosion information to an external location is needed.

To accomplish this, the project is divided into four main tasks related to wireless data transmission, corrosion sensor development, sensor system motion and delivery, and consideration of other pipeline operations issues. In the first year of the program, focus was on sensor development and wireless data transmission. The second year of the program, which was discontinued due to funding shortfall, would have focused on further wireless transmission development, packaging of sensor on wireless, and other operational issues. Because, the second year funding has been discontinued, recommendations are made for future studies.

\section{Wireless Transmission}

Transmission along distances within a pipe was shown to be feasible, and more efficient within the pipeline than for open-air transmissions. Communication from within the pipe to an external receiver occurs at any gap in metallic continuity in the pipe (e.g., non-metallic discontinuities are provided to prevent long-line telluric currents). Alternatively, locations of corrosion coupon in pipeline can be used to extract signals from within the pipe. Communicating the location of the sensor from within the pipe is still a challenge. Ultra Wide Band transmission does not appear to penetrate the pipe consistently. Low frequency 
signal (e.g., AM radio type signal) can penetrate steel and ground cover and should be explored as an alternative.

\section{Sensor Design}

Several sensors were evaluated for use as corrosion sensors on a wireless platform. The interdigitated galvanic couple sensor made of silver-graphite couple was successful at quickly determining general environmental corrosivity, but not actual corrosion rates. The multielectrode array sensor (MAS) probe showed good correlation to corrosion rate of steel. A thin-film flexible version of the MAS probe (TMAS) was developed and shown to function properly. However, the TMAS does not last long in a corrosive environment because of the small thickness of the sensor element. A miniature version of conventional MAS will be used in the resident sensors.

\section{Sensor Power Needs}

Battery power, while a readily available solution, is not a long-term solution. One method of actively powering the sensor is to harvest the energy of moving gas to charge a battery. Several wind mill concepts using small motors were examined. A theoretical analysis indicated that wind driven power transformation is possible. Limited wind tunnel testing showed that wind velocity typical of that expected in a pipeline can generate adequate power for charging the battery. The design of such a power system has to be completed.

\section{Sensor Flow Characteristics}

The effect of gas velocity, sensor density, and pipeline inclination angle on the ability of sensor to move or deposit at a given location was analyzed. The calculations provided a method to develop sensor parameters to enable deposition at a location of water hold-up.

\section{Recommended Future Activities}

Further evaluation of the method to locate the sensor along the pipeline is necessary. Although location using a low frequency signal is possible, this needs demonstration. Alternative location methods must be explored.

The sensor and wireless device should be packaged and the assembly should be tested in a pipeline prior to validation in the field

The durability of the sensor and package should be assessed and, if necessary, improved

The long-term powering of the package should be further explored. Power generation using the gas flow appears to be feasible, but further development of the equipment and demonstration is necessary.

The impact of the sensor package on the operation of pipeline should be assessed. 
SwRI ${ }^{\circledR}$ Project 18.10926 


\section{TABLE OF CONTENTS}

ACKNOWLEDGMENTS _........................................................................... $\quad$ Page

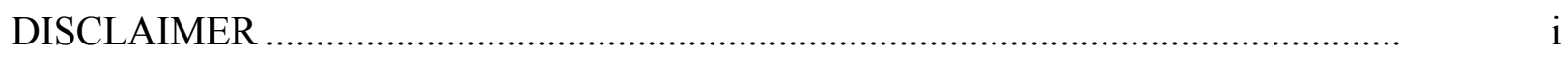

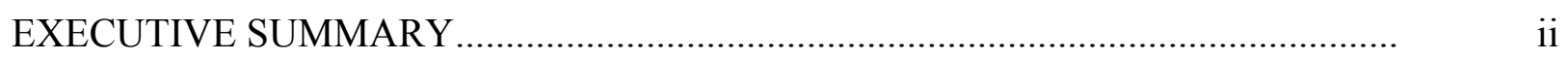

Wireless Transmission ................................................................................... ii

Sensor Design .............................................................................................. iii

Sensor Power Needs ......................................................................................... iii

Sensor Flow Characteristics............................................................................... iii

Recommended Future Activities........................................................................... iii

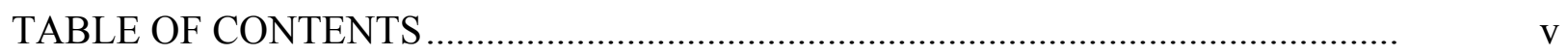

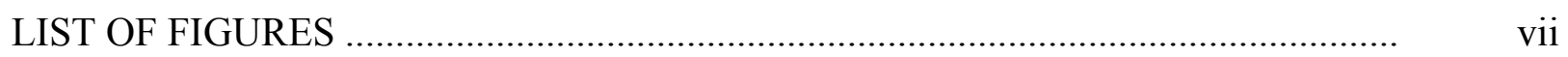

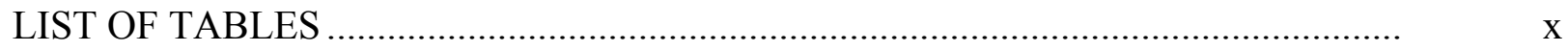

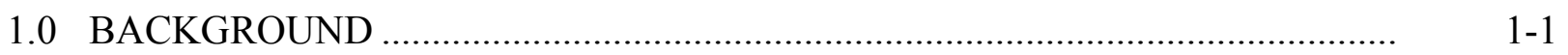

2.0 WIRELESS DATA TRANSMISSION AND ACQUISITION …………………..... $2-1$

2.1 Signal Transmission ................................................................................

2.2 Communication of Sensor Location Information............................................. 2-5

3.0 SENSOR IDENTIFICATION, FABRICATION AND ABILITY ........................... 3-1

4.0 CONCEPTUAL DESIGN OF A SENSOR MOTE SYSTEM ………………..........

4.1 Prototype Development.......................................................................... 4-1

4.2 Sensor Electronics .................................................................................. 4-2

4.2.1 Procedure for Sensor Electronics Development .................................. 4-2

4.2.2 SwRI Developed Test Procedure ......................................................... 4-4

4.2.3 Development Procedure...................................................................... 4.

4.2.4 Repeatability and Reliability....................................................... 4-5

4.2.5 Software Requirements ................................................................ 4-5

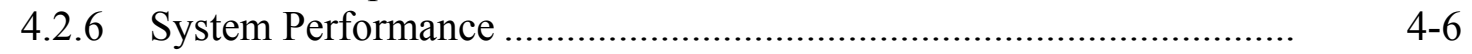

5.0 POWER GENERATION USING GAS FLOW ………………………………....

5.1 Power Requirements for a Sensor Mote System............................................ 5-1

5.2 Introduction to Wind Turbine Power ………………..................................... 5-2

5.3 Power System Design............................................................................. 5

5.4 Windmill Design ..................................................................................

5.4.1 Optimum Conversion of Wind to Shaft Power.................................. 5-5 


\section{TABLE OF CONTENTS (Continued)}

5.4.2 Milli-Generator Survey ..................................................................

5.4.3 Motor Modeling .............................................................................. $\quad 5-7$

5.4.4 Rotor Modeling ............................................................................. 5

5.4.5 Rotor Design Objective ..................................................................... 5-9

5.4.6 Integrated Design Considerations ........................................................ $\quad 5-10$

5.4.7 Rotor Analysis ...................................................................... 5

5.5 Verification and Discussion for Mini-Windmill ............................................ 5-11

5.5.1 Rotor Geometry .......................................................................... $5-11$

5.5.2 Wind-tunnel Demonstration............................................................ $5-12$

6.0 SENSOR MOTION AND DELIVERY TO LOCATIONS OF INTEREST............ 6-1

7.0 SUMMARY AND RECOMMENDATIONS......................................................

7.1 Wireless Transmission .......................................................................

7.2 Sensor Design...................................................................................

7.3 Sensor Power Needs.............................................................................. 7-1

7.4 Sensor Flow Characteristics .....................................................................

7.5 Recommended Future Activities .....................................................................

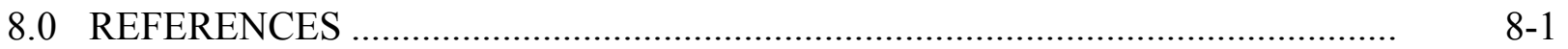




\section{LIST OF FIGURES}

Figure

Page

1-1 Conceptual view of a fluidized sensor

2-1 Non-line-of-sight pipeline wireless data transmission test setup

2-2 Wireless data transmission results comparing the performance of non-lineof-sight internal pipeline communications to line-of-sight communications in air.

2-3 Schematic of 340-foot pipe test loop used for evaluating wireless communications inside pipelines.

2-4 Results comparing relative wireless communications data receipt quality in open air and inside a pipeline.

2-5 Schematic illustration of 80-foot pipe test loop used for pressure, temperature, and relative humidity testing.

2-6 Relative humidity and temperature data obtained using a motes sensor and wirelessly transmitted to a receiver 80 feet away inside a pipeline compared to a hardwired $\mathrm{RH} / \mathrm{T}$ probe.

2-7 6" pipe section with enclosed transmitter (left) used to ascertain UWB transmissibility to antennae receiver (right) within a sealed pipe....

2-8 Schematic of location sensing system for sensors inside pipelines.

3-1 Planar view of thin film interdigitated galvanic couple sensor. This sensor is currently composed of conductive carbon (black line) and silver laid out on Mylar.

3-2 End view of several different versions of the SwRI developed MAS probe.

3-3 Interdigitated sensor response in different environments.

3-4 Relationship between interdigitated sensor response using EIS (impedance modulus at $100 \mathrm{~Hz}$ ) and carbon steel corrosion rate using LPR.

3-5 Relationship between interdigitated sensor response using DC current and carbon steel corrosion rate. 


\section{LIST OF FIGURES (Continued)}

Figure

Page

3-6 Relationship between interdigitated sensor response using DC resistance and carbon steel corrosion rate.

3-7 Comparison of corrosion rates determined using the MAS probe to those obtained using LPR measurements.

3-8 End-on view of a small MAS probe that could be utilized for fluidized sensor applications.

3-9 Illustrated steps in vacuum deposition of thin-film sensors.

3-10 TMAS fabricated with thin-film deposition technology having $\mathrm{Fe}$ electrodes and $\mathrm{Cu}$ leads.

3-11 Schematic of electronics used to monitor TMAS.

3-12 TMAS response to immersion in different solutions. Each trace corresponds to a single electrode in the multi-electrode array........................

3-13 TMAS response reported as corrosion rate.

3-14 Images of TMAS electrodes after test showing significant damage due to corrosion.

3-15 Sensor showing corrosion damage after exposure to simulated pipeline environment for two weeks.

3-16 Post-test appearance of $0.5 \mathrm{~mm}$ steel wire used as ER probe after exposure to $0.1 \mathrm{M} \mathrm{NaCl}$ for nearly 12 weeks.

3-17 Diameter loss due to corrosion measured using electrical resistance for 0.5 $\mathrm{mm}$ steel wires exposed to different possible internal pipeline corrosion environments.

4-1 Schematic of a Sensor Mote (SM) showing the various components envisioned in the full system..

4-2 Major components of sensor system.

4-3 Measuring electronics. 


\section{LIST OF FIGURES (Continued)}

Figure

Page

5-1 Stream tube.

5-2 Ideal power which can be extracted from a $2 \mathrm{~cm}$ radius gas steam tube.......

5-3 Power system architecture.

5-4 Expected range of power system component efficiencies.

5-5 Optimum-geometry rotor shaft power as a function of rotor radius for air at $5.4 \mathrm{~m} / \mathrm{s}$ (negative values denote power flowing from the rotor, consistent with propeller theory convention).

5-6 Motors tested (top to bottom): Maxon RE8, Mabuchi 8127, Mabuchi 7Z75.

5-7 Predicted output for an optimal rotor driving at Mabuchi 7 Z75 motor/generator at a gas velocity of $5.4 \mathrm{~m} / \mathrm{s}$.

5-8 Predicted output for an optimal rotor driving a Maxon RE8 261509 motor/generator at a gas velocity of $5.4 \mathrm{~m} / \mathrm{s}$.

5-9 Photo of $2 \mathrm{~cm}$ radius rotor on Maxon RE6 motor/generator.

6-1 Schematic of force balance for spherical sensors moving inside a pipeline. .

6-2 Critical incline angles that can be climbed as a function of gas velocity for a 1.5 inch probe with different densities.

6-3 Critical incline angles that can be climbed as a function of gas velocity for a 1.0 inch probe with different densities.

6-4 Critical incline angles that can be climbed as function of gas velocity for a 0.5 inch probe with different densities.

6-5 Critical incline angles that can be climbed as a function of gas velocity for a 2.0 inch probe at different pipeline operating pressures. 


\section{LIST OF TABLES}

Table Page

5-1 Pipeline Environmental Conditions ……………...................................... 5-2

5-2 Wireless Sensor System Power and Energy Requirements ........................... 5-2

5-3 Commercially Available Small Motors ………............................................... 5-6 


\subsection{BACKGROUND}

Over the last two years, The Office of Pipeline Safety (http://ops.dot.gov/stats/stats.htm) attributes approximately 14 and $12 \%$ of natural gas and liquids transmission pipelines accidents, respectively, to internal corrosion. Internal corrosion of natural gas transmission lines has caused significant economic loss as well as loss of life. Therefore, assessing the location and extent of internal corrosion is an important aspect of pipeline integrity management. The internal corrosion damage is assessed using several techniques:

- In many cases, pipelines are periodically inspected using intelligent pigs and their results verified by excavation and detailed examination at selected sites. However, this often results in service disruptions and considerable costs. Further, a significant portion of the pipeline system is unpiggable because of various geometrical and geographical constraints.

- Internal corrosion direct assessment (ICDA) is being evaluated as an alternative to traditional ILI methods and also holds promise for non-piggable lines (Moghissi et al., 2002, 2003; Burwell et al., 2004; Khale et al., 2004). ICDA relies on fluid flow modeling to determine the critical pipeline inclination angles that will be likely sites for water accumulation. Several sources of uncertainties exist with ICDA, including flow parameters, pipeline inclination angles, and the distance from the critical angle along the pipeline over which corrosion damage is likely to occur. Thus, excavations or other inspection methods still must be employed near the locations where water holdup is predicted.

- Non-intrusive monitoring tools such as the Field Signature Method (FSM) monitor or guided wave devices have been used to monitor internal corrosion. The main limitation of these tools is the need for prior identification of locations to emplace the sensors. FSM is said to be able to identify localized corrosion, but is confined to a narrow region around its installation point. The guided wave devices can measure corrosion over longer distances (several hundred yards along the pipe), but do not have sufficient resolution to detect localized corrosion. Further, excavation of pipe to install the sensors can be expensive or even impossible depending on the location. For example, in a recent pipeline study, although ICDA suggested inspection of a certain location along the pipeline, difficulties relating to obtaining environmental permits for excavation prevented excavation and installation of inspection/monitoring devices.

Thus, there is a need to develop a sensor system that can enter the pipeline, move along the fluid stream, deposit at various locations to sense the presence of a corrosive electrolyte, and communicate that information to an outside receiver for processing. This report presents the results of the first year of a project with an overall objective to develop sensors that will meet the above needs. A conceptual picture of the spherical sensors is shown in Figure 1-1. The sensor resides on the outer surface of a hollow ball and is electrically connected to wireless computer platform residing inside the ball. At present, the wireless platform and the sensor are powered by conventional batteries. The power consumption is managed by an on-board computer. The 


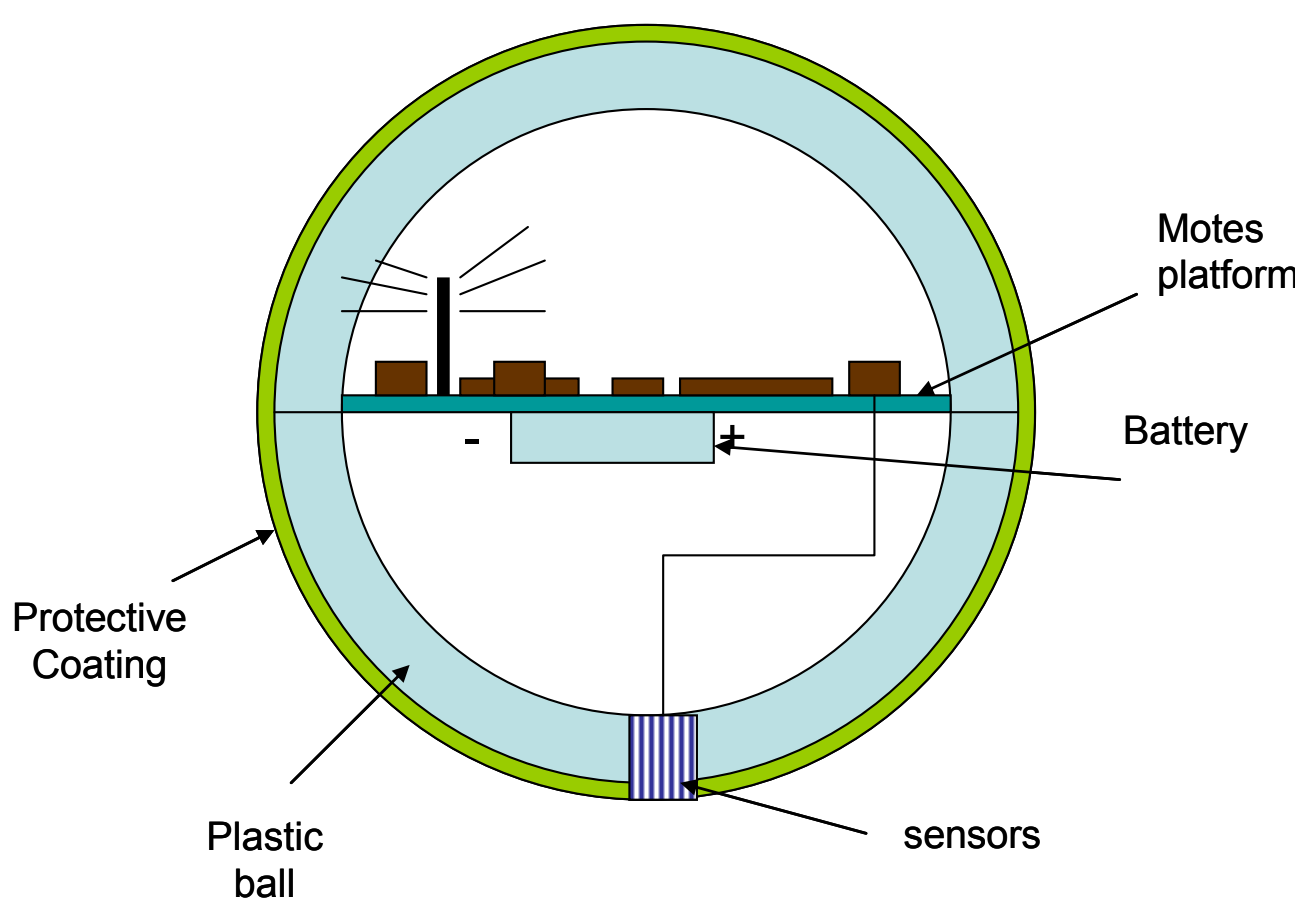

Figure 1-1. Conceptual view of a fluidized sensor.

wireless platform, communicates with other sensors introduced in the pipe and with the external world at access points where electromagnetic signals can be extracted. In implementing such a sensor system, the following issues need to be addressed:

1. Communication between sensors and from within the pipe to the external world

2. Ability to determine location of the sensor along the pipe

3. Ability of sensors to detect water and measure corrosivity

4. Ability of sensors to differentiate between bulk water accumulated in the pipe and moist gas stream that could form a thin condensed film on the sensor

5. Response time of the sensor

6. Sensor life

7. Power consumption and life of the power system

8. Integrity of the sensor + wireless package as it rolls down the pipe

9. Effect of sensors on other equipment (filter screens, machinery, etc.)

10. Fire and explosion hazards

11. Other operational issues: introduction, retrieval costs, equipment, etc.

It can be seen from the above list that within a finite project resource and time table, all the above issues cannot be fully addressed. In the first year of the project, attention was focused on corrosion sensor development, the ability to communicate with the external world, sensor life, and power consumption. A limited study of the ability to determine location was conducted. Recommendations are made for further studies. These issues were addressed in parallel tasks and a sensor package (sensor plus wireless system inside the ball) has not yet been evaluated. 


\subsection{WIRELESS DATA TRANSMISSION AND ACQUISITION}

\subsection{Signal Transmission}

The main goals of this task were to determine whether wireless transmission within a pipeline is technologically feasible, what influence operating conditions may have on such transmissions, what data transmission distances might be achievable, and ultimately how to extract the data from the sensor network and use it to make decisions regarding pipeline integrity. Initial tests were conducted using short pipe test loops of 20 to 80 foot lengths and pipe diameters of 18, 6, and 3 inches (Figure 2-1). Initial efforts clearly demonstrated that wireless data transmission inside the pipeline were feasible. Furthermore, the signal strength observed inside the pipeline in non-line-of-sight situations was greater than that noted for lineof-sight transmissions in the air (Figure 2-2).

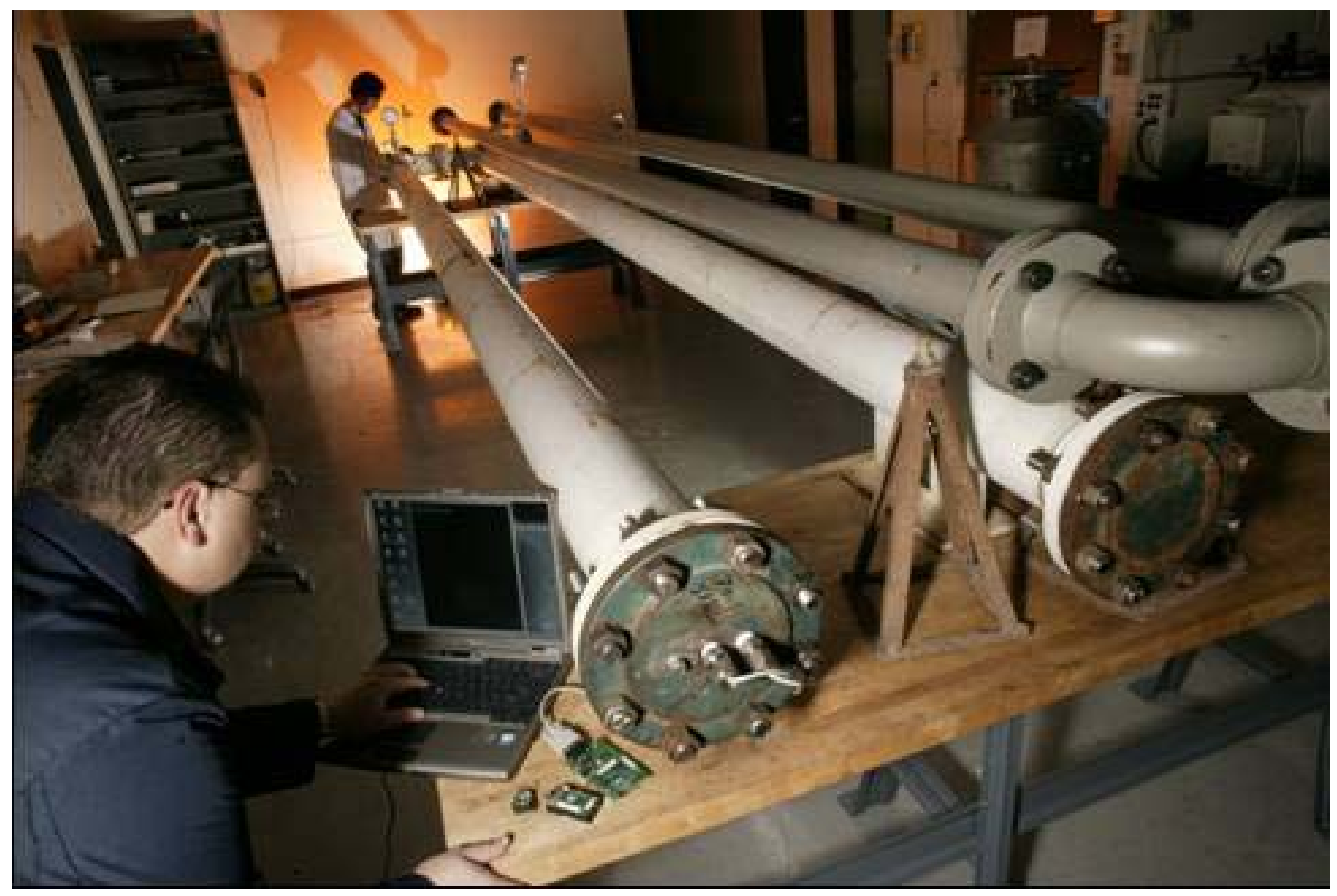

Figure 2-1. Non-line-of-sight pipeline wireless data transmission test setup.

Testing was conducted on a 340 foot test loop in which the overall data transmission quality and signal strength were measured. A schematic of the test loop is shown in Figure 2-3. It should be noted that the long pipe loop consisted of several different pipe diameters ranging from 8 to 12 inches with multiple bends, elbows, and reducers/enlargers. Sealing the sensor mote in the pipeline at the opposite end of the loop from the receiver ensured that signal transmission could only occur within the pipeline and not through the air between the pipe ends (which was verified). When compared to the same system in air, a significant improvement in the overall transmission range inside the pipe is noted (Figure 2-4). For example, at a distance 
of 200 feet only approximately $25 \%$ of the data packets are received when the transmission is carried out in the open whereas $100 \%$ are received inside the pipeline. This finding clearly shows that transmission of the signal inside the pipe is not only feasible, but the pipe acts as a waveguide and boosts the transmission range of the sensor signal.

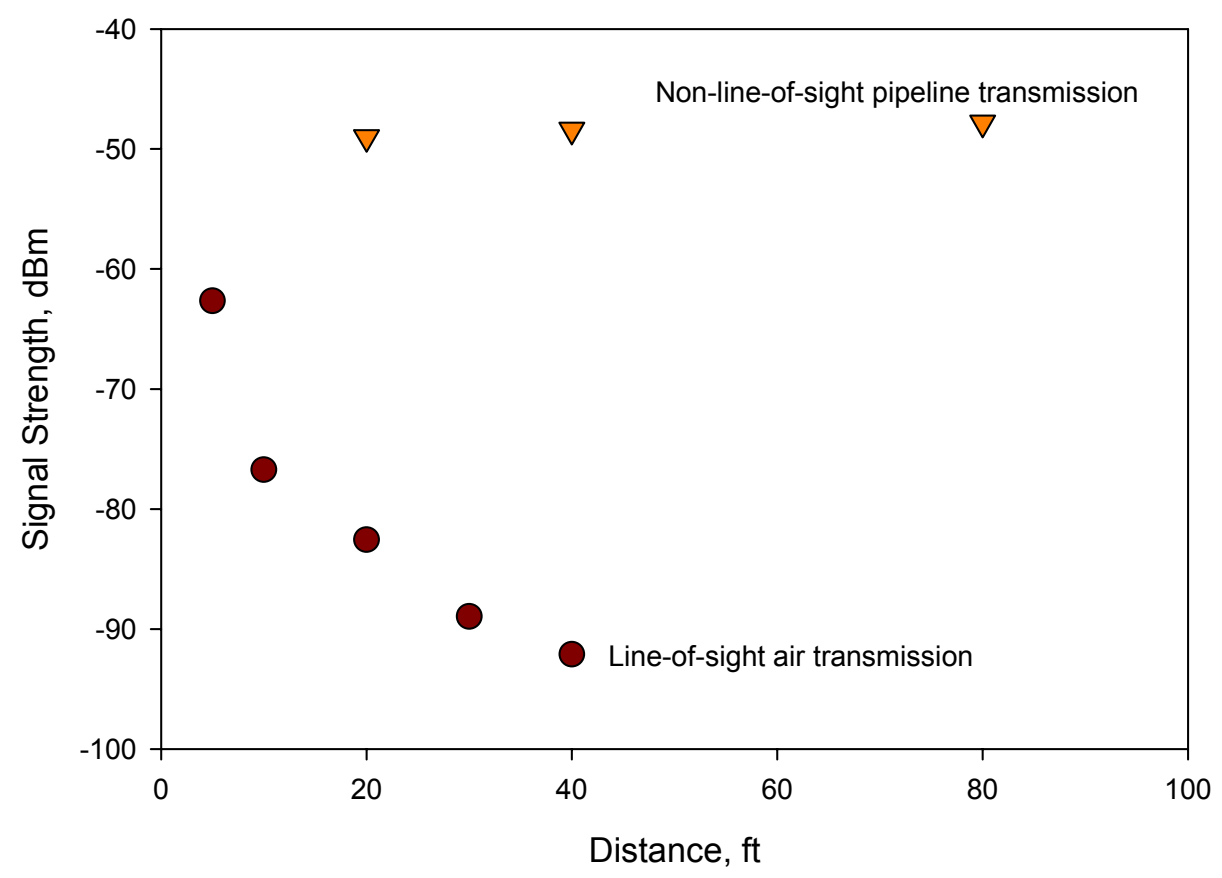

Figure 2-2. Wireless data transmission results comparing the performance of non-line-of-sight internal pipeline communications to line-of-sight communications in air.

To further examine point-to-point wireless communications inside pipelines, an 80-foot test loop was constructed in which the pressure, relative humidity, and temperature can be varied and independently measured (Figure 2-5). A series of tests were then conducted in which the pressure was slowly increased and the response of the motes sensor was compared to the gauge pressure. Because the motes pressure sensor was only valid to pressures up to $1.1 \mathrm{bar}$, and the tests were conducted at a pressure of approximately 1.5 bar, no accurate measurements were made using the motes system. Temperature and relative humidity measurements made with the motes system proved to be both highly accurate as well as responsive as shown in Figure 2-6. Thus, the motes sensor is not only exhibited excellent communications capabilities from point to point inside the pipeline but it also is able to provide highly accurate and responsive condition monitoring as well. Additional tests were conducted at lower temperatures $\left(15.5^{\circ} \mathrm{C}\right)$ to determine whether signal transmission and sensor readings were affected by the temperature. The lower temperature was maintained at one end of a pipe look using an external chiller. The motes sender was located at this end. The motes receiver was located outside the pipe. Data transmission was still excellent and the difference in the readings was less than 6 percent. 


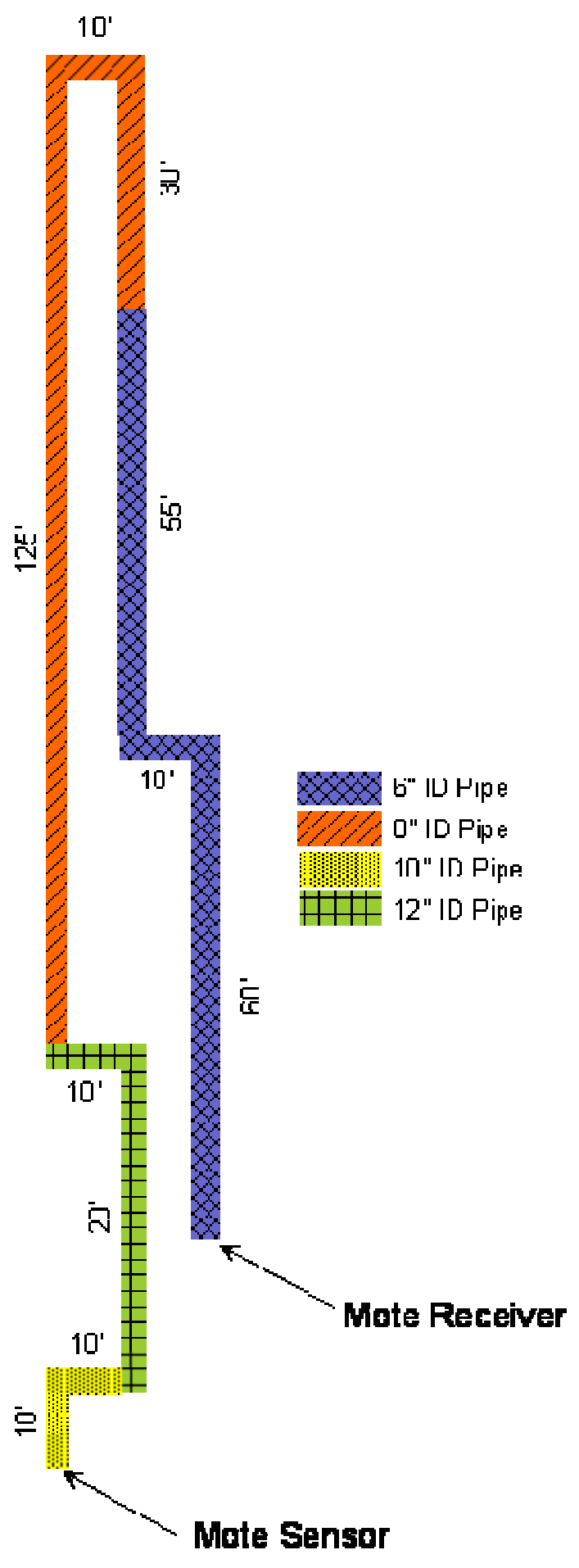

Figure 2-3. Schematic of 340-foot pipe test loop used for evaluating wireless communications inside pipelines. 


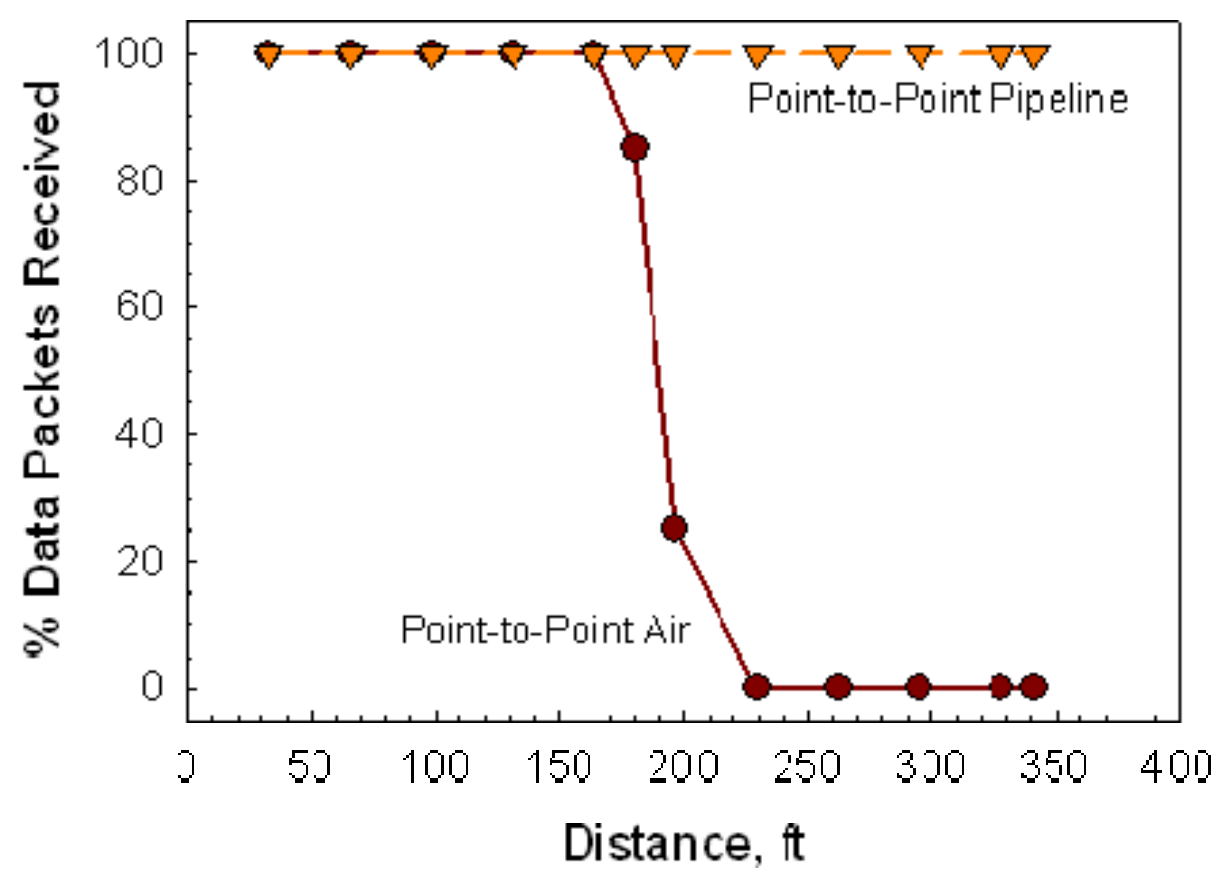

Figure 2-4. Results comparing relative wireless communications data receipt quality in open air and inside a pipeline.

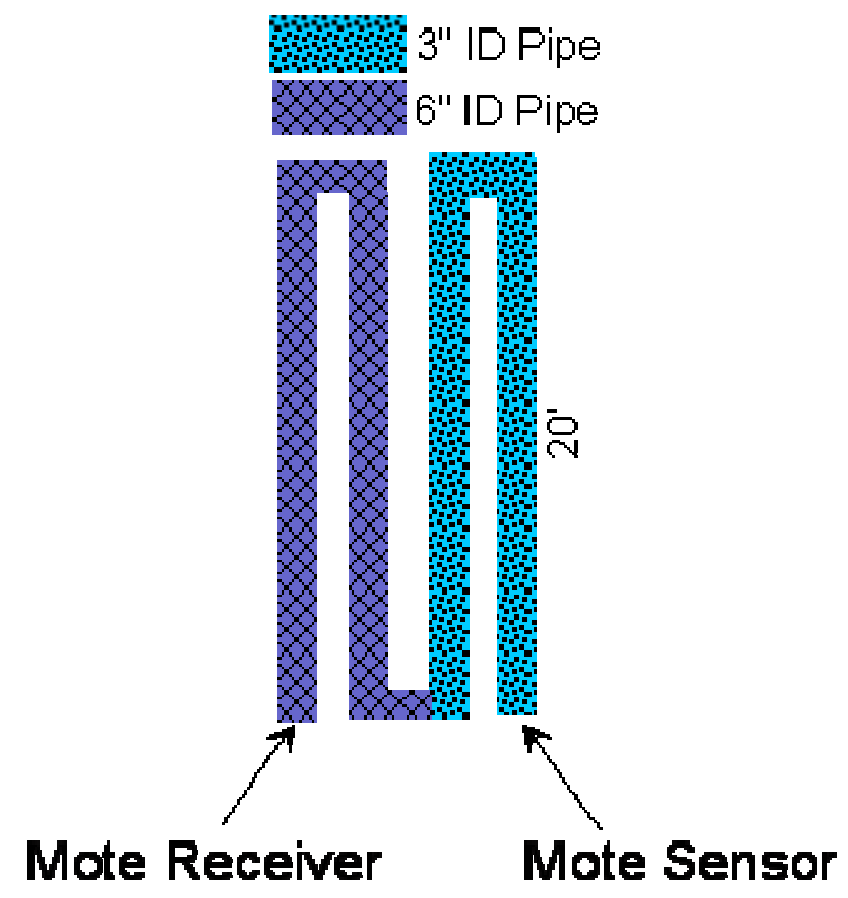

Figure 2-5. Schematic illustration of 80-foot pipe test loop used for pressure, temperature, and relative humidity testing. 


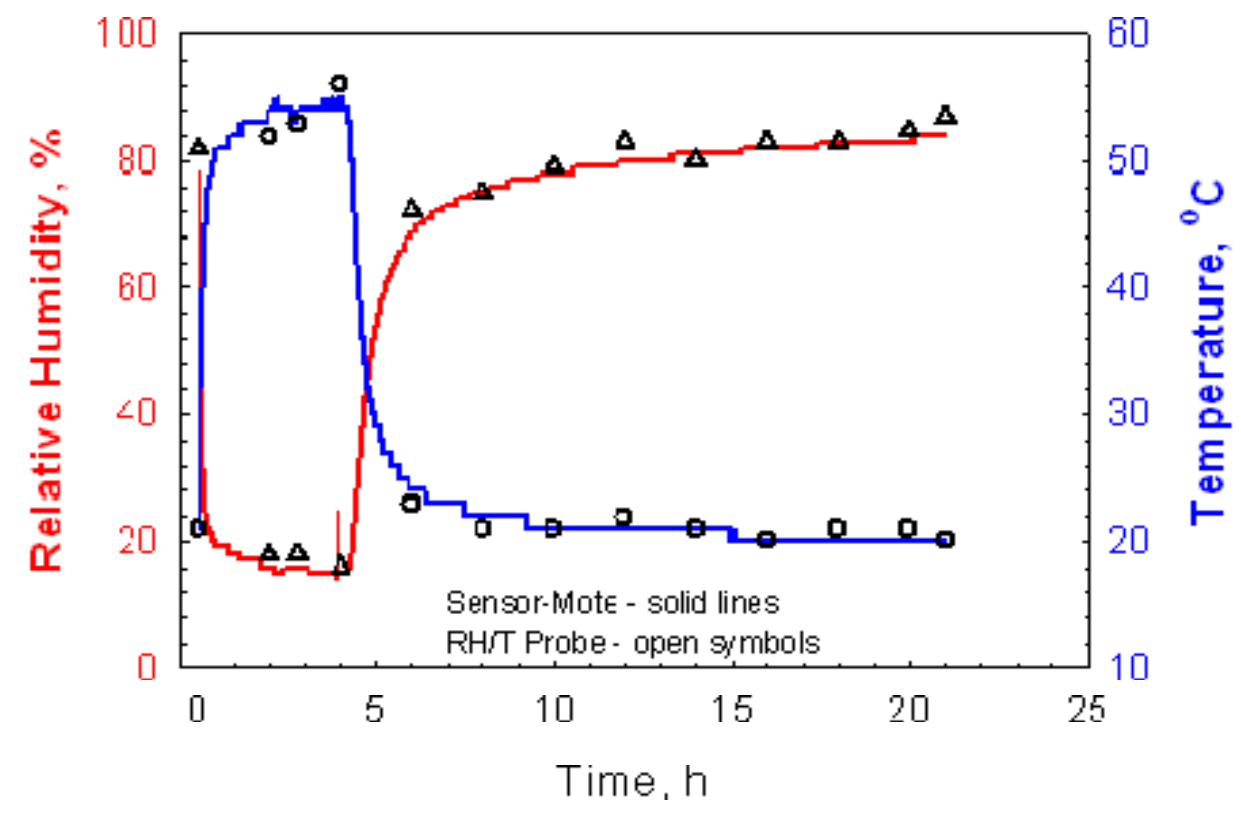

Figure 2-6. Relative humidity and temperature data obtained using a motes sensor and wirelessly transmitted to a receiver $\mathbf{8 0}$ feet away inside a pipeline compared to a hardwired $\mathrm{RH} / \mathrm{T}$ probe.

\subsection{Communication of Sensor Location Information}

Ultrawide Band (UWB) signals and low-frequency radio waves were identified as possible methods with which to locate a sensor within a pipeline. UWB signals have been used in conjunction with radio frequency identification (RFID) tags to track assets, and shown to transmit signals through shipping containers. An evaluation was performed to determine if UWB signals could propagate through a sealed pipeline. A $35 \mathrm{~mW}$ and a $1 \mathrm{~W}$ UWB transmitter were placed and sealed in steel pipelines of 4 and 6" (Figure 2-7) diameters with pipewall thicknesses of $1 / 4 "$. The low power tag could not be read when sealed in any of the pipes, while the high-powered tag showed erratic readings in the 6" pipe at close range $(<1$ foot $)$ and all readable signal diminished at a 10 foot range. The high-powered tag could not transmit when sealed in the 4" pipe. The unreliable transmission of UWB signal in these pipes, coupled with the severely reduced range compared with open-air ranges $(<10$ feet from $>1100$ feet $)$ indicates that UWB may not be a suitable solution for sensor location.

An alternative approach that has not been tried in this project at this time will be the use of low-frequency radio waves. This approach is known to transmit signal out of the ground as well as through buildings (AM radio), however the accuracy of the location has yet to be determined. Various sectors of the underground utilities industry have used low-frequency locating devices for many years to locate, or locate and transmit data (AM or FM) to underground structures. In directional drilling for utility installation, locating under four feet of groundcover can be done within a one-foot accuracy when there is no signal distortion or interference. Some relatively simple above ground experiments with prototype equipment and pipe should indicate whether or not this is a feasible approach. 


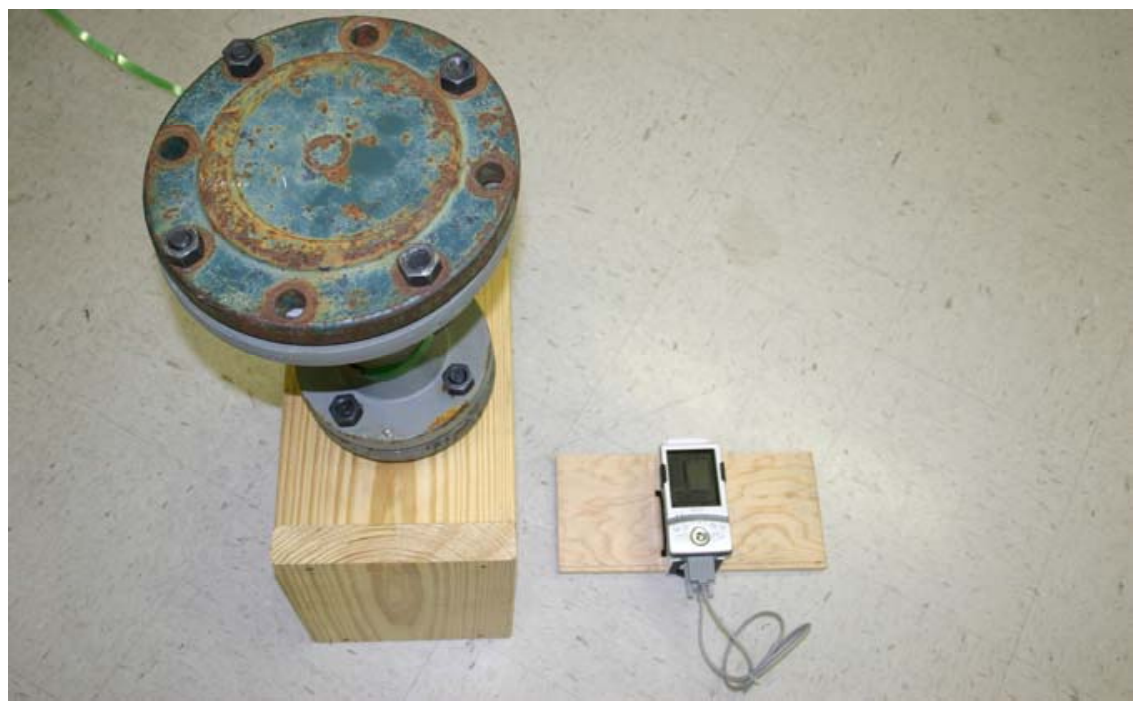

\section{Figure 2-7. 6" pipe section with enclosed transmitter (left) used to ascertain UWB transmissibility to antennae receiver (right) within a sealed pipe.}

Since lower radio frequencies (RF) are better conducted through solid material like steel they require less energy to transmit. A low frequency RF ping system could be designed to work in conjunction with the mote. Figure 2-8 shows schematically the process of using low frequency signal to locate the sensor inside pipes. Location would be determined based upon a GPS reading transmitted from above ground user to the mote sensor. The user would be moving above ground in a direction parallel to the pipe. When the user is directly above the sensor mote in the pipe, the radio signal should be peak and thus this radio transmitted GPS location would be confirmed in the sensor mote computer. Additional study needs to be performed to understand the feasibility of accurately determining the sensor location based upon this method. Important considerations include multiple pipe depths, pipe material and pipe wall thicknesses. Other logistical considerations for adapting to a mote platform would be the small antenna size, and power requirements required.

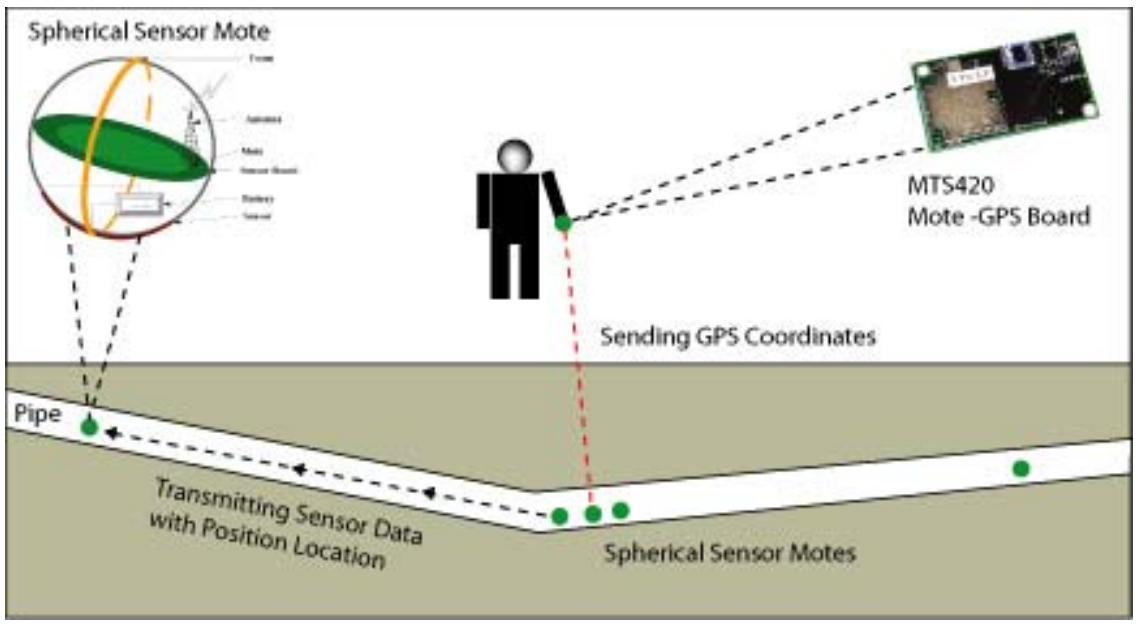

Figure 2-8. Schematic of location sensing system for sensors inside pipelines. 


\subsection{SENSOR IDENTIFICATION, FABRICATION AND ABILITY}

A main objective of this task was to identify corrosion sensors that can accurately and reliably indicate if water accumulation has taken place and if the accumulated water possesses a significant corrosion risk. To accomplish this, the chosen sensor must be able to distinguish between accumulated water and the accumulation of other less corrosive electrolytes (e.g., glycol) as well as be able to quantify different levels of environmental corrosivity. Three different sensors were identified and tested for efficacy as a pipeline corrosivity sensor. These sensors consist of an interdigitated carbon-silver galvanic couple thin-film sensor (Figure 3-1), the SwRI developed multielectrode array sensor (MAS) probe (Figure 3-2), and small electrical resistance probes constructed using fine $0.5 \mathrm{~mm}$ diameter steel wires.

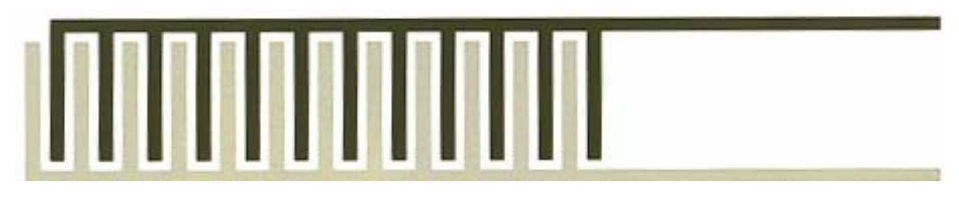

Figure 3-1. Planar view of thin film interdigitated galvanic couple sensor. This sensor is currently composed of conductive carbon (black lines) and silver laid out on Mylar.

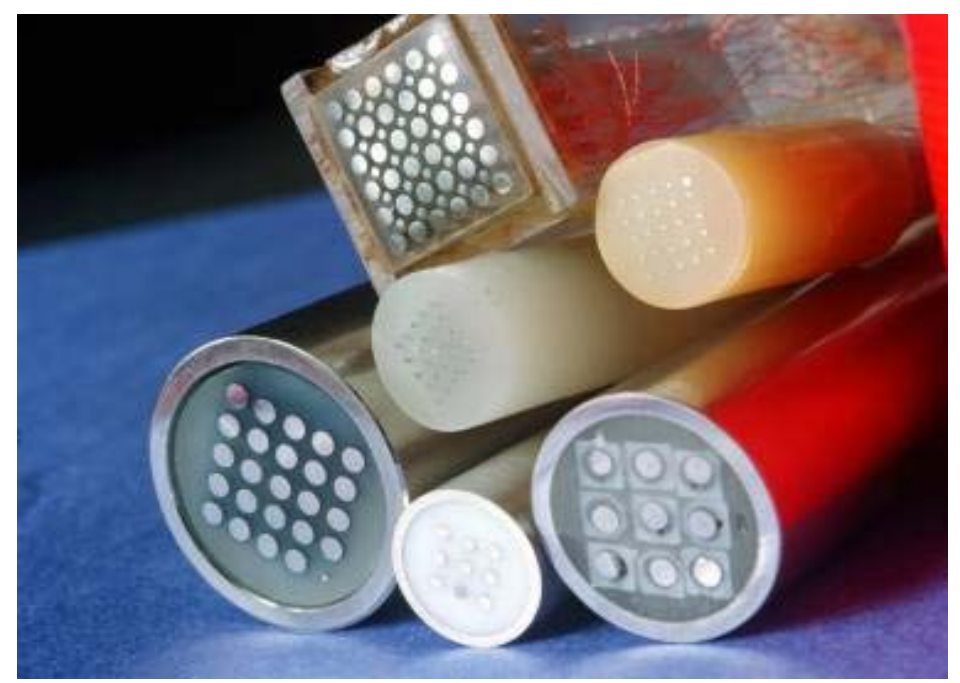

Figure 3-2. End view of several different versions of the SwRI developed MAS probe.

The interdigitated galvanic couple sensors were evaluated under ambient temperature and pressure conditions in a glass vessel. The galvanic couple sensor was evaluated by measuring the DC resistance between the elements, the DC current flow between elements, the potential difference between the elements, and by using electrochemical impedance spectroscopy to determine the AC impedance between the elements. Each of these measurements was compared to the corrosion rate of carbon steel measured using linear polarization resistance in the same environments. The environments examined included deionized water, glycol, and combinations 
of the two containing moderate concentrations of sodium chloride or sodium bicarbonate. Figures 3-3 - 3-6 illustrate some of the key results obtained. In examining the different possible interrogation modes, the sensor DC current (Figure 3-5) and resistance (Figure 3-6) measurements appear to offer the best signal fidelity and correlation with the actual carbon steel corrosion rate. This is a critical observation, as the materials utilized in this couple sensor (conductive carbon or graphite and silver) have no bearing or relationship with the expected corrosion characteristics of pipeline steel. Yet, a relatively good relationship exists between the sensor response and steel corrosion rate.

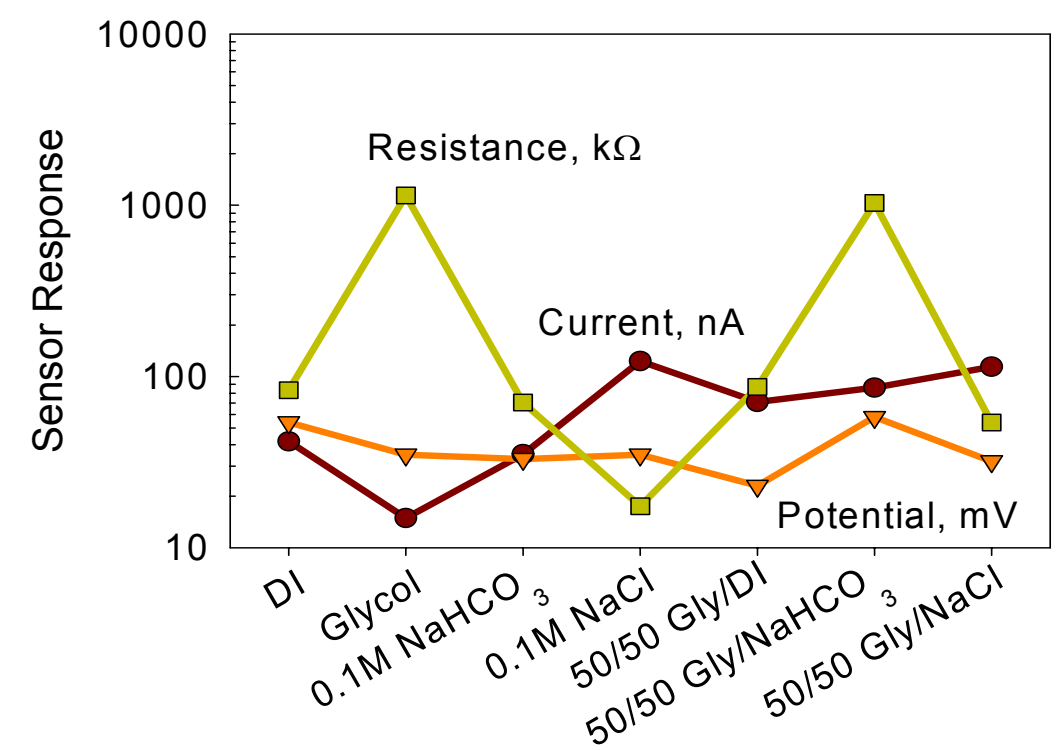

Figure 3-3. Interdigitated sensor response in different environments.

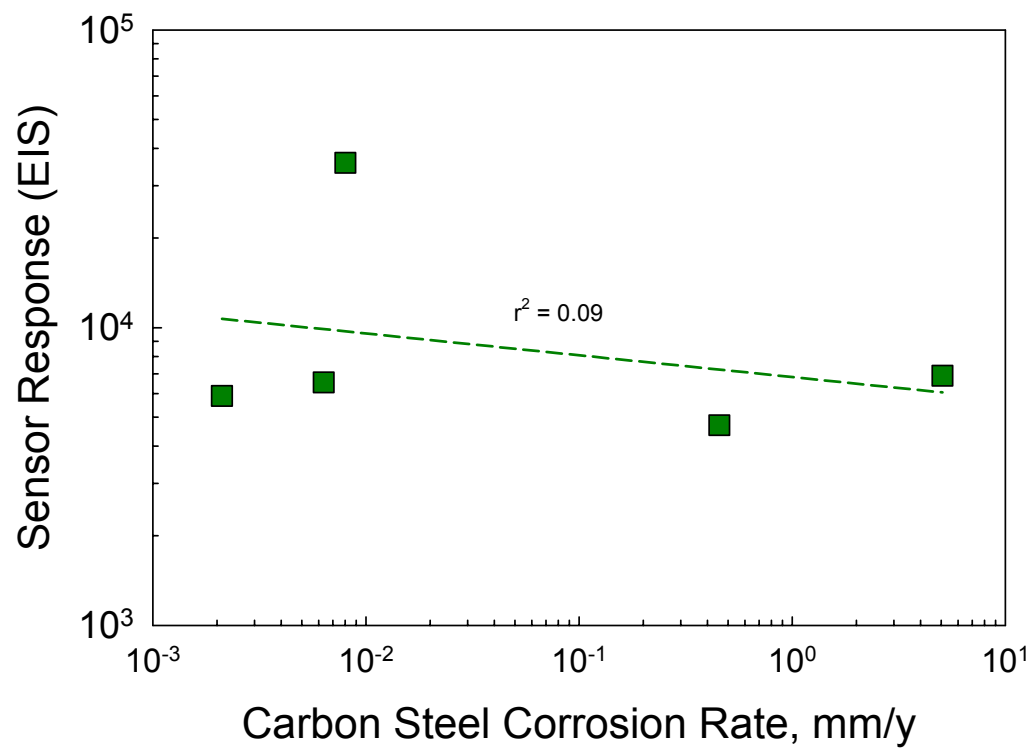

Figure 3-4. Relationship between interdigitated sensor response using EIS (impedance modulus at $100 \mathrm{~Hz}$ ) and carbon steel corrosion rate using LPR. 


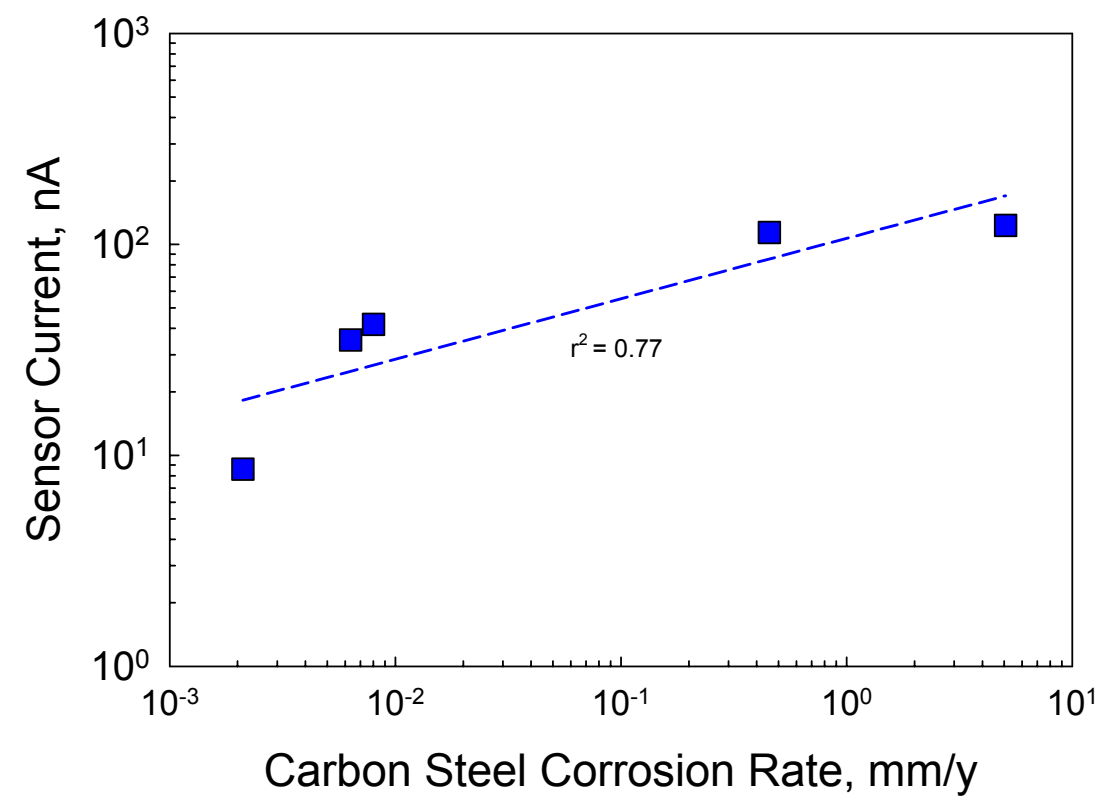

Figure 3-5. Relationship between interdigitated sensor response using DC current and carbon steel corrosion rate.

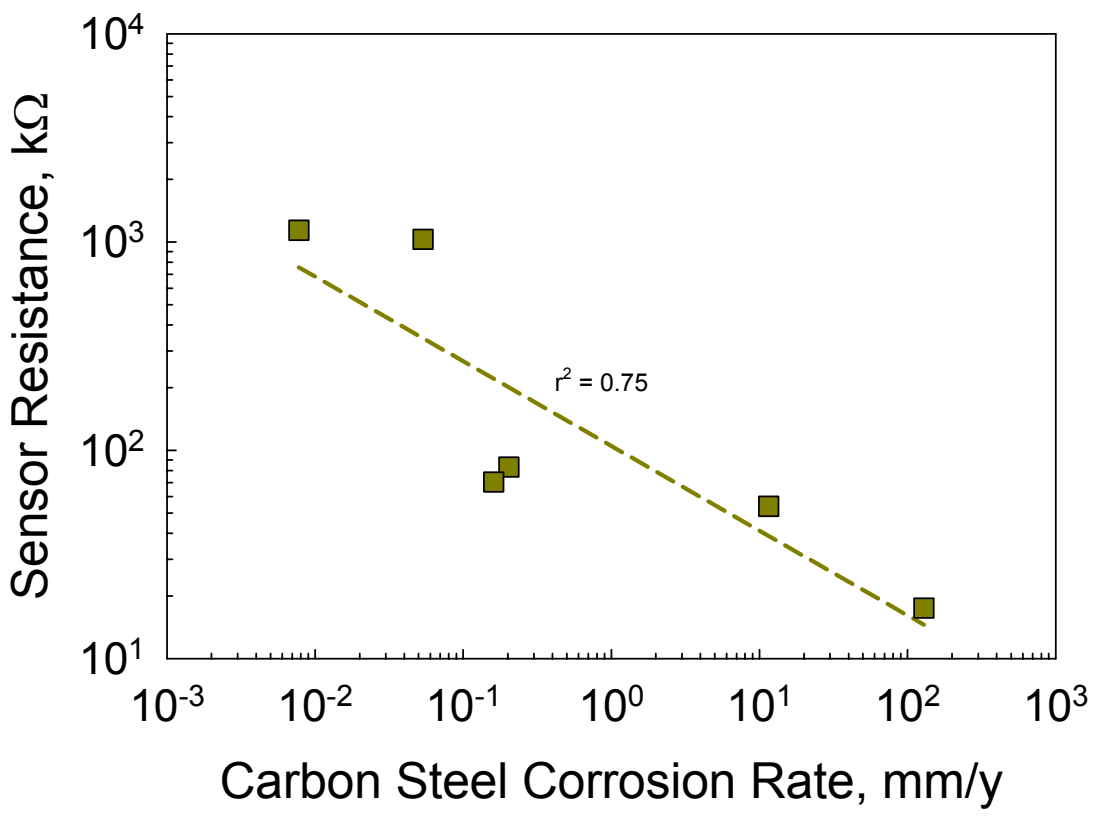

Figure 3-6. Relationship between interdigitated sensor response using DC resistance and carbon steel corrosion rate.

Despite the encouraging results obtained using the interdigitated galvanic couple sensor, it cannot provide an actual measure of steel corrosion rate, especially if localized corrosion is involved. Because of this, a carbon steel MAS probe was evaluated under identical conditions (Figure 3-7). The results indicate a clear relationship and excellent correlation between the corrosion rates measured using the MAS probe to that obtained using LPR. 


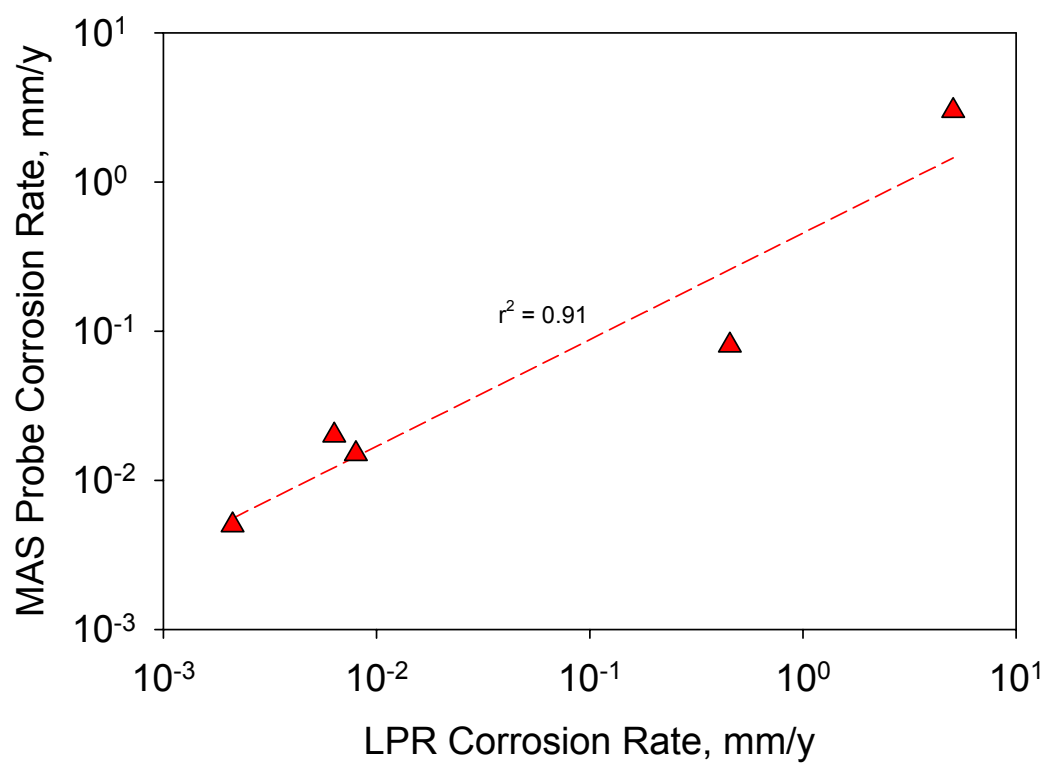

Figure 3-7. Comparison of corrosion rates determined using the MAS probe to those obtained using LPR measurements.

The primary constraint in using the MAS probe for the present application is its physical size. This constrain arises because the MAS probe was originally developed to monitor localized corrosion in chemical process streams as a stationary device. To overcome this obstacle, alternative designs and fabrication methods were developed to adapt the MAS probe to this system. Specifically, a lighter, non-clad MAS plug consisting of wire electrodes in a nonconductive polymeric matrix, and a flexible circuit thin-film design of the MAS were conceived. The MAS plug could be constructed in the traditional methods for the larger, stationary device, but with the advantages of smaller size and lighter weight. An image, showing a smallscale MAS probe is shown in Figure 3-8. This probe in this image is clad with the traditional stainless steel tube, but is shown for the size of scale possible with the traditional fabrication techniques.

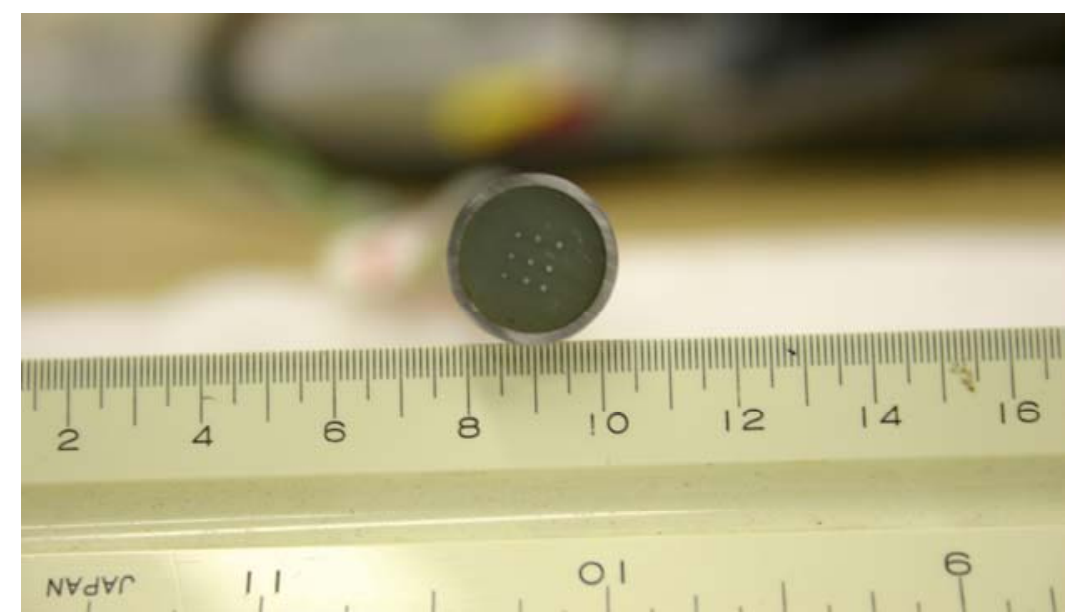

Figure 3-8. End-on view of a small MAS probe that could be utilized for fluidized sensor applications. 
An alternative to the MAS-plug is a thin-film flex circuit design of the MAS probe (TMAS). A thin profile would allow the probe to be used as the "skin" of a fluidized sensor. Thin-film fabrication technologies would also favor more efficient sensor fabrication that is easily adapted to large-scale production. A schematic illustration of vacuum deposition techniques used in thin-film flex-circuit fabrication is provided in Figure 3-9. The "shadow mask" in the illustration is reusable, and may be designed for fabricating batches of sensors in a single deposition.

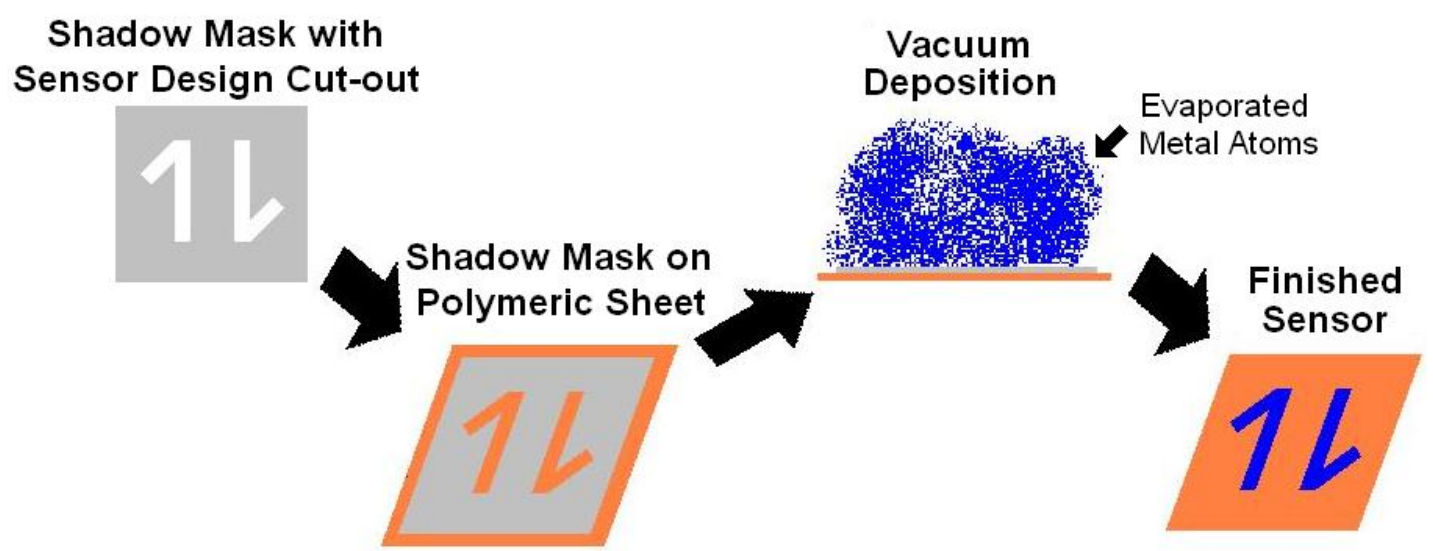

Figure 3-9. Illustrated steps in vacuum deposition of thin-film sensors.

Machining complementary shadow masks that allow for multi-step depositions where different metals with intricate designs may be deposited on the same sensor footprint may enhance the process illustrated in Figure 3-9. Figure 3-10 shows an image of a completed, vacuum deposited, thin-film MAS probe, hereafter referred to as TMAS.

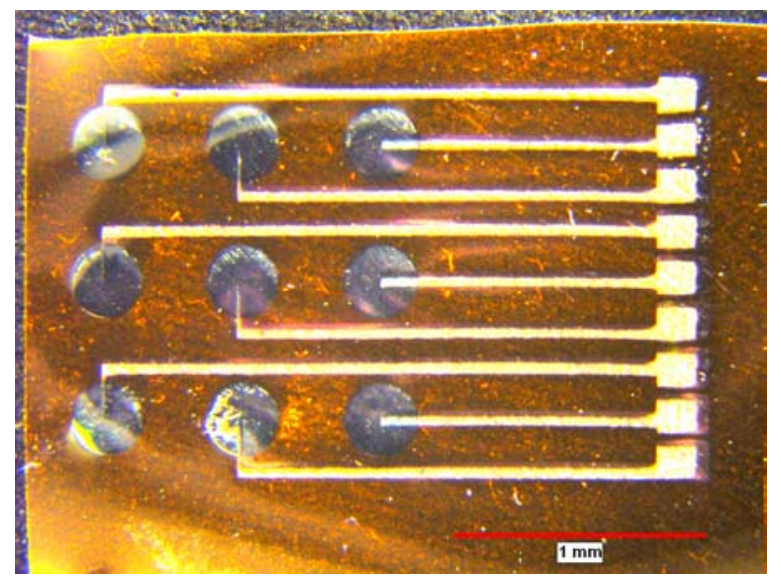

Figure 3-10. TMAS fabricated with thin-film deposition technology having Fe electrodes and $\mathrm{Cu}$ leads.

The TMAS (as well as the MAS) works by simulating a single piece of corroding metal. During localized corrosion, several of the electrodes will act as anodic sites while others will act cathodically as a result of the localized corrosion. By electrically isolating the electrodes at the 
corrosion interface, but electrically connecting the electrodes through external electronics, the user may channel and measure the corrosion current while minimally disturbing or altering the corrosion phenomenon. In order to monitor the electrode activity of the TMAS, a schematic circuit diagram of the electronics stage is shown in Figure 3-11. To determine current, a nano-voltmeter coupled to a multiplexer was used to measure the potential across each $100 \Omega$ resistor.

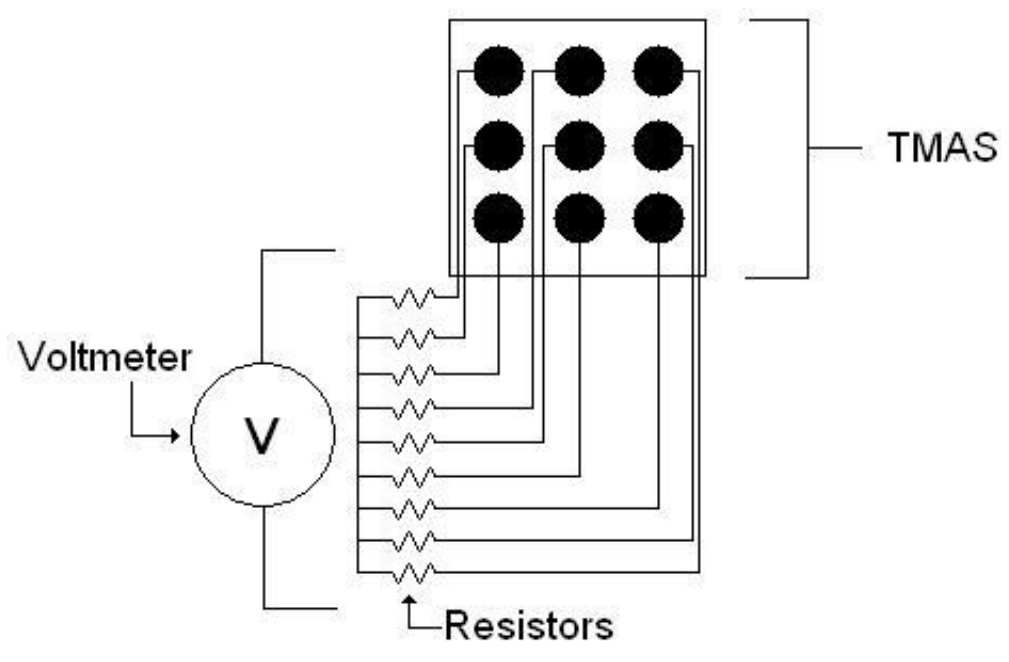

Figure 3-11. Schematic of electronics used to Monitor TMAS.

TMAS was then tested by immersing at room temperature in deaerated deionized water (17-18 M $\Omega$ ) for approximately 75 minutes, followed by immersion in a deaerated $0.5 \mathrm{M}$ $\mathrm{NaCl}$ solution for 30 minutes, and then reimmersion in the deionized water 20 minutes. For a properly functioning TMAS, there should be little current flow during immersion in the water, but a significant increase in currents due to corrosion in the $\mathrm{NaCl}$ solution (Figure 3-12).

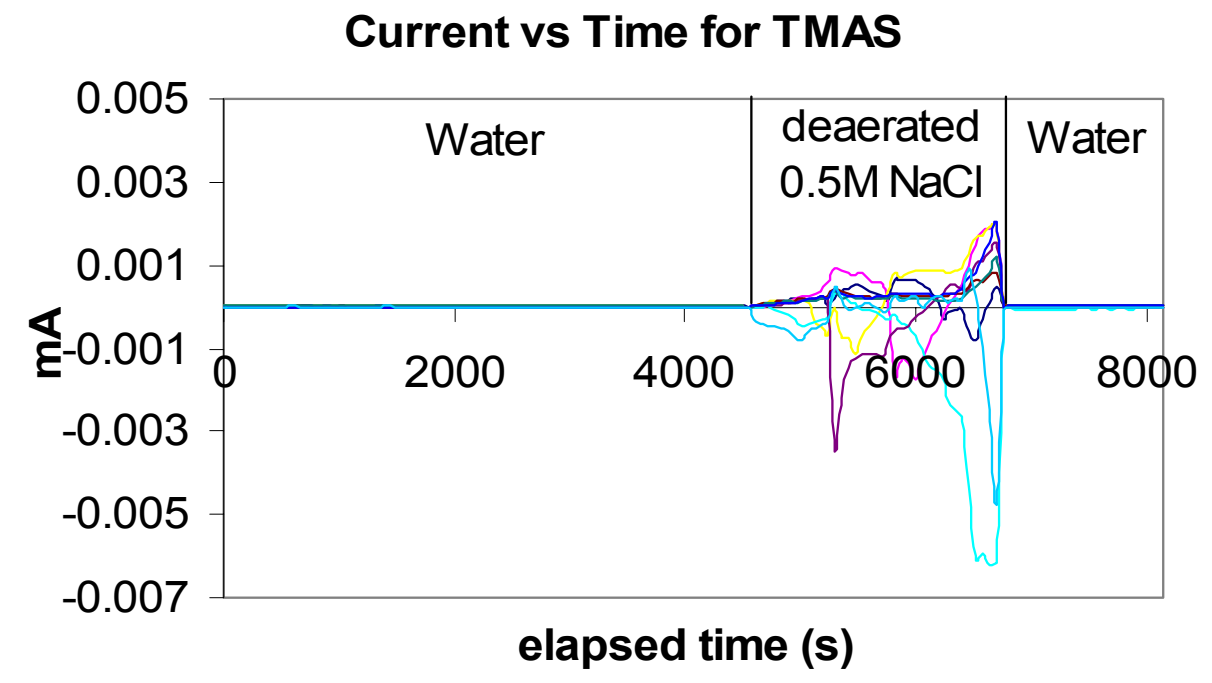

Figure 3-12. TMAS response to immersion in different solutions. Each trace corresponds to a single electrode in the multi-electrode array. 
The sensor response clearly shows a marked increase in activity in the aggressive environment, compared to the immersion in deionized water. The sensor responded quickly to changing environments. The recorded current measurements from all nine electrodes may be analyzed statistically and converted to corrosion rate. As an example, the maximum anodic current recorded from all of the electrodes at each given time increment may be taken and converted to a real-time corrosion rate (Figure 3-13).

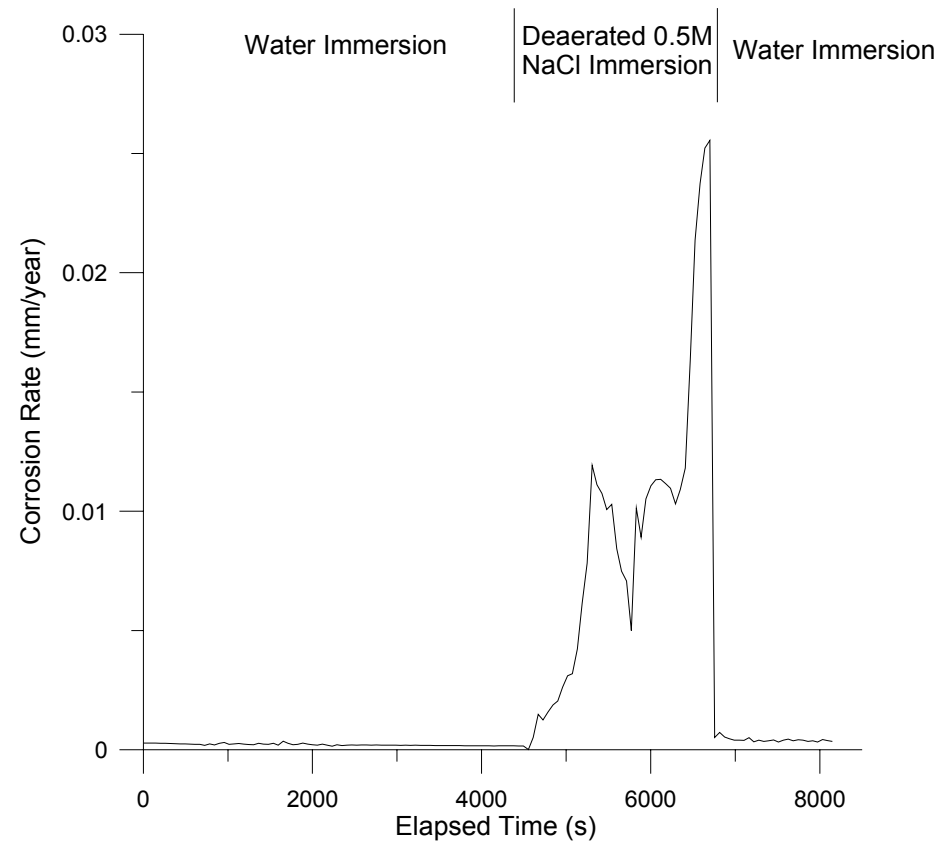

Figure 3-13. TMAS response reported as corrosion rate.

A disadvantage to using vacuum deposition technologies is the quantity of material deposited. For corrosion sensors, where the sensor itself is unavoidably consumed during the sensing process, sensor lifetime should be a design consideration. The small material dimensions involved with thin-film technologies place a practical limit on the sensor life. To illustrate this, Figure 3-14 contains several images of the TMAS electrodes after the immersion test. These electrodes show pitting consistent with the data in Figure 3-13.
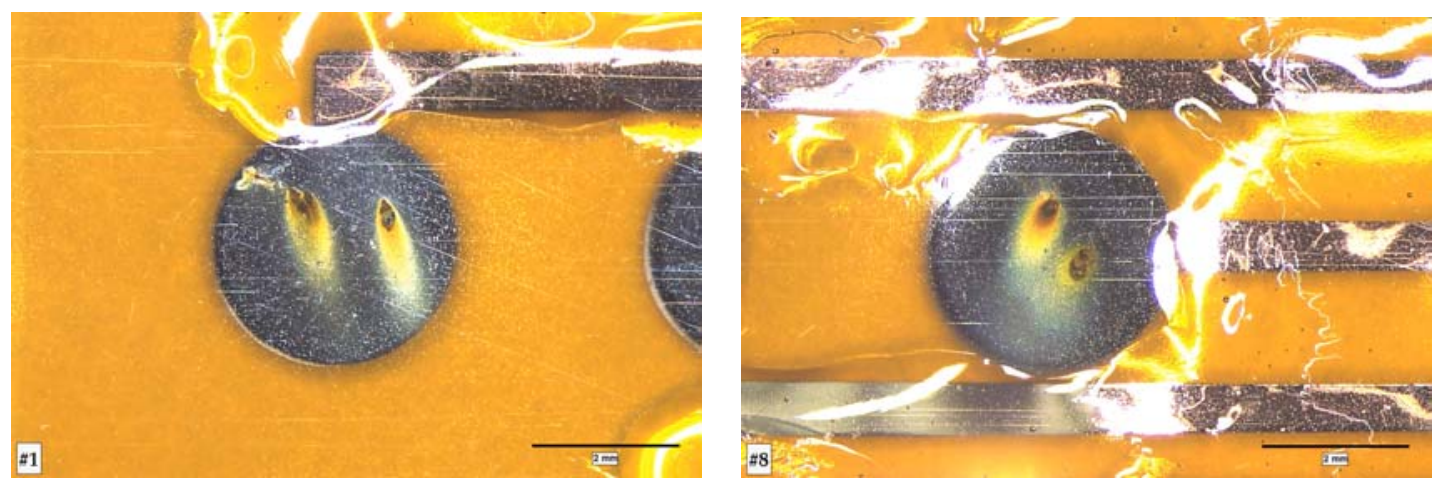

Figure 3-14. Images of TMAS electrodes after test showing significant damage due to corrosion. 
To further explore the possible sensor lifetime expectations for a thin-film corrosion sensor, a TMAS was immersed in a dilute solution of $\mathrm{NaOH}$, placed in an autoclave and pressurized to 500 psi with a gas mixture containing 1.03 percent $\mathrm{CO}_{2}$ and 0.01 percent $\mathrm{H}_{2} \mathrm{~S}$. This simulates a natural gas meeting tariff gas quality limit for $\mathrm{CO}_{2}$, but much higher than typical tariff limit (4 ppm) of $\mathrm{H}_{2} \mathrm{~S}$. The initial $\mathrm{pH}$ was 11.58 and end $\mathrm{pH}$ was 5.52. The sensor was left in the environment for 2 weeks. This sensor after the 2-week exposure is shown in Figure 3-15.

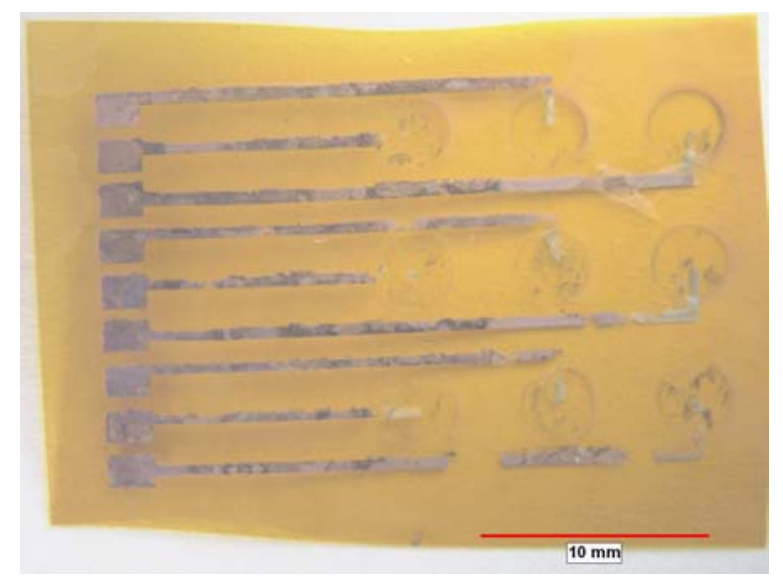

\section{Figure 3-15. Sensor showing corrosion damage after exposure to simulated pipeline environment for two weeks.}

Clearly, the thin-film sensor could not withstand the exposure. Thin-film sensors by themselves may not be suitable for long-term sensing in aggressive environments. Depositing alloy materials instead of pure metals, exploring methods to efficiently deposit larger quantities of materials including longer deposition times and electroless plating techniques, or even by manually affixing electrode discs to thin-film circuits, may mitigate these sensor life-limiting issues. Another important issue with MAS is the complexity of the electronics required. Miniaturizing the electronics to measure low currents accurately will be a significant challenge.

The possibility of constructing electrical resistance (ER) probes utilizing small diameter wires to provide an indication of corrosion was also examined. Steel wires with a diameter of $0.5 \mathrm{~mm}$ were exposed to deionized water, glycol, $0.1 \mathrm{M} \mathrm{NaHCO}_{3}$, and $0.1 \mathrm{M} \mathrm{NaCl}$ and the resistance monitored using a multichannel, high input impedance voltmeter. During corrosion of the wires, the diameter (cross sectional area) will decrease as a function of time resulting in an increase in resistance. Figure 3.16 shows the post-test appearance of a wire after exposure to $0.1 \mathrm{M} \mathrm{NaCl}$ for nearly 12 weeks. Despite using a highly sensitive multimeter to monitor wire resistance, no definitive change in diameter was detectable until after 10 hours of exposure (Figure 3.17). For a sensor that would remain in place to perform long term monitoring, this may prove to be an appropriate monitoring method. However, if the sensor is intended to pass through the pipeline from one point to another and be extracted from the pipeline without a long residence time, the ER probe approach is likely not viable due to the length of time needed to obtain a reliable measurement of corrosion. 


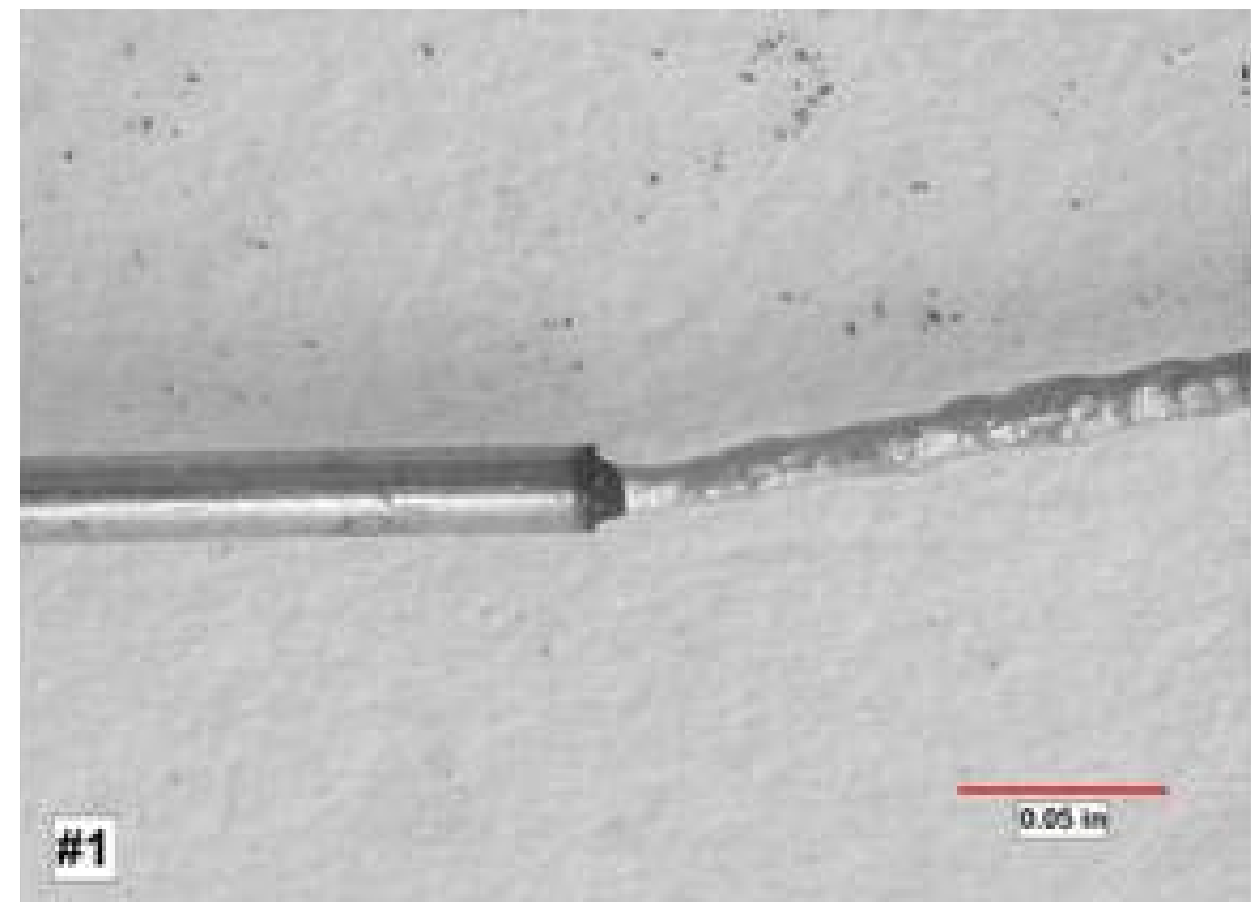

Figure 3-16. Post-test appearance of $0.5 \mathrm{~mm}$ steel wire used as ER probe after exposure to $0.1 \mathrm{M} \mathrm{NaCl}$ for nearly 12 weeks.

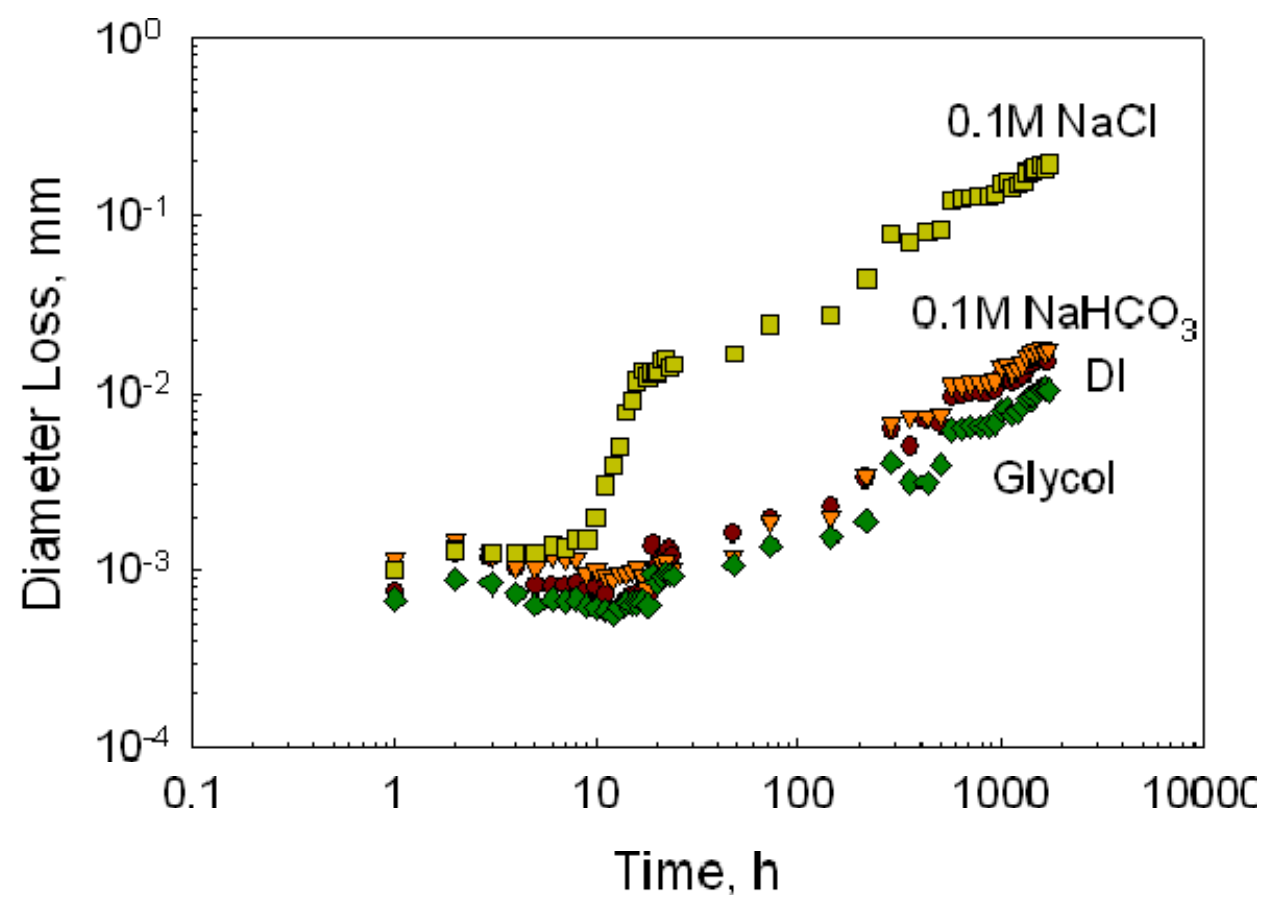

Figure 3-17. Diameter loss due to corrosion measured using electrical resistance for $0.5 \mathrm{~mm}$ steel wires exposed to different possible internal pipeline corrosion environments. 


\subsection{CONCEPTUAL DESIGN OF A SENSOR MOTE SYSTEM}

This section outlines a conceptual design of a packaged sensor system. Depending on the situation one or all the methods could be used.

- Combination of permanently resident sensor with a "messenger sensor to collect data periodically: The "messenger" sensor-mote (SM) can be inserted at inspection sites by rolling or floating inside the pipeline. The messenger SM package then rolls by - uploads data from permanently resident SM that is on site then passes it on to the base station.

- $\quad$ Once-Through Retrievable Sensor: The SM is introduced into the pipe, travels along the pipe making measurements, and is then retrieved at another location to extract data. This method gives a value once and is appropriate to confirm ICDA prediction based on pipeline operating conditions.

- $\quad$ Resident SM based Mesh network: The SM is left in place and communicates the data to the outside world through an optimum wireless communication path (e.g. at a metallic gap in a joint or through a corrosion coupon introduced periodically in the pipe). This approach provides real-time data at any time during the sensor life.

\subsection{Prototype Development}

The preferred prototype shape for the SM is a sphere. Figure 4-1 shows a schematic with all the elements of a Spherical sensor mote system. The components of the SM include:

(a) Outside shell

(b) Mote transceiver

(c) Antenna

(d) Battery

(e) Sensor Electronics

(f) Wetting agent - Foam material

(g) Sensors

The prototype will need to have the following functionalities to evaluate it in actual pipeline condition in the lab and in the field:

- $\quad$ Size \& Shape - Spherical 1.5-2” diameter

- Weight $10-20 \mathrm{~g}$

- $\quad$ Packaging - coating or foam

- $\quad$ Motes - Crossbow's just released OEM version of postage stamp 2.5GHz wireless transceiver 
- $\quad$ Sensor - SwRI developed sensors

- Sensor Electronics - to be developed; specification in the next section

- $\quad$ Power source - coin cell batteries for testing; in future harvest energy from the gas flow inside pipeline described in later sections

- $\quad$ Smart software - to discern false positives

- $\quad$ Location sensing unit - needs development

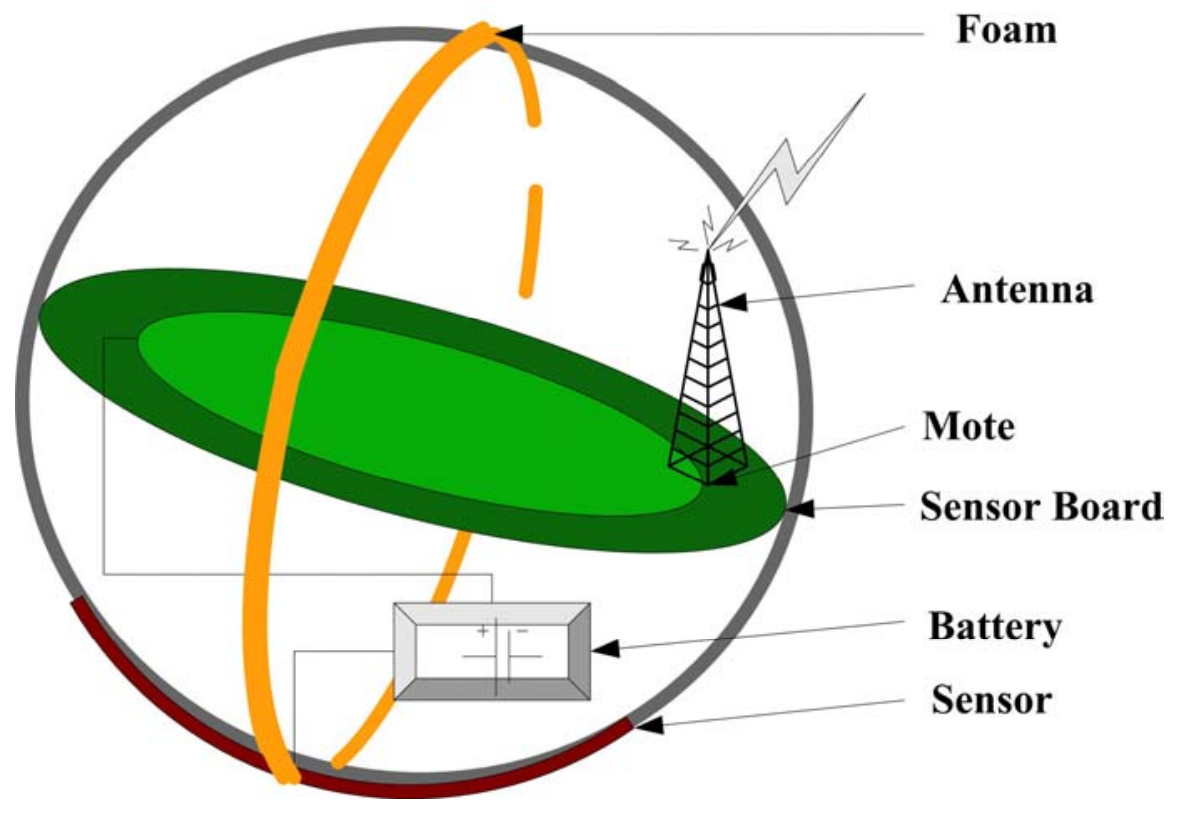

Figure 4-1. Schematic of a Sensor Mote (SM) showing the various components envisioned in the full system.

\subsection{Sensor Electronics}

\subsubsection{Procedure for Sensor Electronics Development}

An instrument will be designed which will be able to report the corrosivity of a liquid. It will consist of three major components: (See Figure 4-2.)

1. A thin-film corrosivity sensor that will contact the liquid, and be composed of two dissimilar metal electrodes so as to form a galvanic couple.

2. An electronic stage that will interface the corrosivity sensor with the microcontroller located on the MOTE module. The electronics module will be used to perform a corrosivity assessment via a DC resistance measurement between the sensor electrodes. 
3. A MOTE transceiver stage that will enable wireless communications between the measurement electronics and an external unit.

The corrosivity sensor measurement consists of a two-electrode direct current (DC) resistance measurement. In developing the sensor, a digital multi-meter (DMM) was used to record a resistance measurement. For the fluidized versions, an ohmmeter circuit will be needed to measure the DC resistance. Assuming we will need to measure a maximum of $2 \times 10^{6} \Omega$ with $1 \times 10^{3} \Omega$ resolution, a $2 \mathrm{~V}$ potential should be applied across the electrodes.

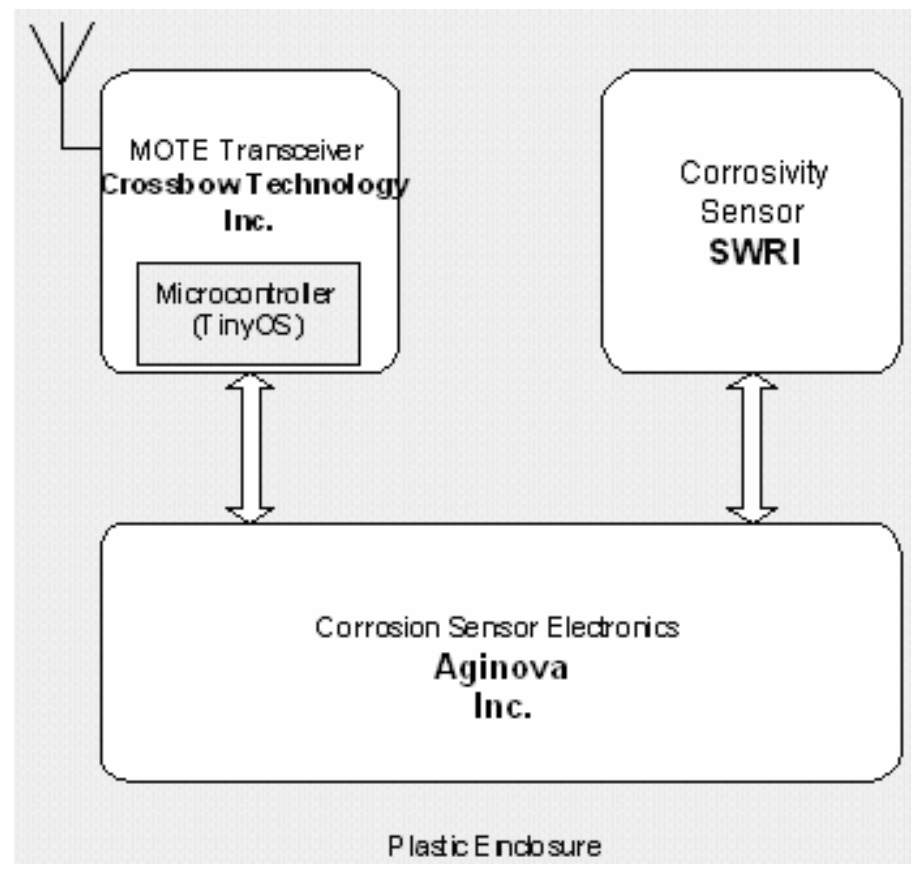

Figure 4-2. Major components of sensor system.

The conducted current is then measured with an ammeter having microampere resolution. The measured current is then converted to resistance using Ohm's law. The magnitude of the resistance measured will determine whether the liquid is of a corrosive type (low resistance) or non-corrosive type (high resistance). The threshold for determining corrosivity has yet to be determined, and sensors may need to be calibrated with test solutions before deployment (fluidized).

Electronics will be developed as needed to interface with the Corrosivity Sensor to perform a DC resistance type measurement. The DC resistance measurement will be used to evaluate the corrosivity of the contacted liquid. A LabVIEW based program incorporating National Instruments hardware that will interface with the custom electronics will also be designed. The LabVIEW system will provide a graphical user interface (GUI) through which the user can initiate a corrosion measurement and display the results. (See Figure 4-3). 


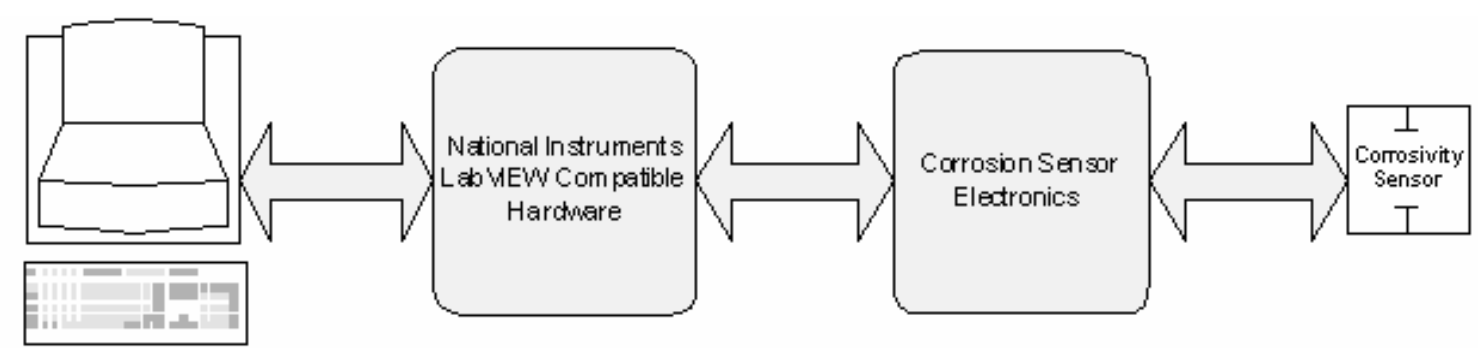

LabVEWGUI

Figure 4-3. Measuring electronics.

\subsubsection{SwRI Developed Test Procedure}

To ensure the sensor prototype system meets expected results, the following testing procedure will be utilized:

1. Prepare three corrosion sensors.

2. Immerse sensors and record a measurement (Step 3) sequentially in the series of liquids listed below.

a. 50/50 by volume solution of deionized water and Ethylene Glycol.

b. $0.1 \mathrm{M} \mathrm{NaHCO}_{3}$ in deionized water.

c. $0.1 \mathrm{M} \mathrm{NaCl}+0.1 \mathrm{M} \mathrm{NaHCO}_{3}$ in deionized water.

d. $0.1 \mathrm{M} \mathrm{NaCl}$ in deionized water.

3. Record a DC resistance measurement during immersion for each of the above liquids.

a. A known voltage will be applied across the electrodes.

b. The current will be measured with the electronics/software system. The software will calculate and report resistance in $\mathrm{kOhms}$.

c. Step b should be repeated at integral times for up to 5 minutes to ensure the measurement is stable.

d. Step b may also need to be performed with a delay (current measured a second or two after electrodes are energized) in order to ensure a representative measurement.

\subsubsection{Development Procedure}

1. Determine the required operating parameters to validate the performance of each module System Block Diagram. (See Figure 4.)

2. Investigate various circuit configurations which will be candidates for implementation of the functionality required by each module of the block diagram.

3. Prototype each candidate circuit and validate the performance as an independent unit as per the required parameters defined in Step 1. 
4. Integrate each functional prototype circuit block into a single prototype of the entire design as per the block diagram.

5. Integrate the prototype electronic system with LabVIEW based software via National Instruments data acquisition hardware.

6. Validate system performance as per the System Requirements document.

7. Iterate Steps 3 through 5 as necessary to achieve successful Step 6.

\subsubsection{Repeatability and Reliability}

The test procedure outlined above will be repeated ten times for each sensor. The sequence of liquids will be varied to ensure that the measurement obtained for each liquid is representative of that liquid. The measurements will also be taken at different times of immersion, starting with an immediate measurement upon immersion, up to a measurement after 5 minutes of continuous immersion in the test liquid. The results will be statistically evaluated for mean and standard deviation, as well as a plot showing the measurement value versus the immersion time for each liquid and sensor pairing.

\subsubsection{Software Requirements}

The GUI will meet the following expectations:

- Install quickly and easily onto a PC running LabVIEW software.

- $\quad$ Provide a user-friendly interface.

- $\quad$ Provide rapid results when invoking liquid corrosivity information.

- Facilitate the exportation of information to databases or other programs.

The GUI will also incorporate the following user input control and output indicators:

- Input

1. Sensor serial number

2. Sensor specific information and notes

3. Run mode (i) Single measurement (ii) Time-stamped measurement (for measurement vs. immersion time readings)

4. Start measurement button

- $\quad$ Output Display

1. Resistance indicated numerically

2. Time-stamp ( down to the second)

- Integration with communications software

1. Provide support in integrating the algorithms with the motes

- Detailed documentation of how the drivers work

- Work with Aginova in providing guidance on getting the drivers to work with the motes 


\subsubsection{System Performance}

The system will be able to measure with the following performance:

- $\quad$ Resistance magnitude

○ Minimum Range: $1 \times 10^{3}-500 \times 10^{3} \Omega$

- Resolution: $1 \times 10^{3} \Omega$

- Preferred Range: $1 \times 10^{3}-2 \times 10^{6} \Omega$

- Resolution: $1 \times 10^{3} \Omega$ 


\subsection{POWER GENERATION USING GAS FLOW}

\subsection{Power Requirements for a Sensor Mote System}

The continuing microelectronics revolution combined with advances in wireless networking has enabled the concept of distributed networks of very small, smart wireless sensors. There is much research, a vast literature, and many emerging products in this area, the review of which is beyond the scope of this work. While the applications and approaches for such networked sensors vary widely, they share one challenge in common. Unless an external power source is available, such as the power mains or vehicle supply, energy and power can be a major design constraint.

For cases in which external power is not available, the choices for power and energy can be considered as being in one of two categories, onboard energy storage and energy harvesting. In onboard storage, energy must be stored in chemical form onboard the sensor. This chemical energy is then converted to power as needed. Today, this chemical energy is usually stored in batteries which serve both as the energy storage medium and the power converter. Typical battery energy density is $180-220 \mathrm{Whr} / \mathrm{kg}$ for widespread primary lithium chemistries and about half that for rechargeable. There is a battery design tradeoff between energy density and power density. Specifically, the rate at which energy can be extracted from a battery (its power density) trades adversely with the maximum energy per unit volume which can be stored (its energy density). The performance of advanced batteries for military applications may improve by $20-30 \%$ in the next $3-5$ years, although this effort is primarily aimed at relatively large sizes and power levels.

While, there is much research and development work on other chemical energy storage approaches such as fuel cells and micro heat engines, none are now available at the small sizes needed. Also, devices as demonstrated do not yet exceed the overall performance of the best batteries. For these approaches, the fuel supply and power converter are separate.

For applications in which batteries cannot store sufficient energy, energy harvesting can be considered. Energy harvesting refers to extracting the energy from the environment around the sensor. Because environmental energy sources are typically intermittent, this harvested energy is generally used to charge an onboard battery which serves as the direct power source for the electronics. Energy sources considered for harvesting include solar wind, water, temperature gradients, changes in atmospheric pressure, and vibration. Of these, the solar provides the highest energy density even at high latitudes. With the exception of solar, the power levels realizable from centimeter sized energy harvesting schemes under ambient conditions are at the nanowatt rather than the microwatt or milliwatts level. This implies that for remote, wireless sensor networks, design for low energy consumption is a primary design imperative and that for many applications, the available power source will be a determinant of the system's size, economics, and even viability. For the first phase of the work, we will consider conventional batteries.

For long-term, resident design, we have examined the theoretical feasibility of extracting sufficient energy from the gas velocity in a natural gas pipeline to power a wireless transceiver. 
This power system must be consistent with the geometry of about $1 / 2$ of a two inch diameter sphere. The environmental conditions in the pipeline are stated in Table 5-1. Since the properties of natural gas are a function of its composition, which can vary according to the source and process, we will be conservative by assuming that the density of the gas is that of methane (it may be greater than that by $5-10 \%$ ). We will also assume that any energy and power system must be capable of operating under the worst combination of these conditions.

Table 5-1. Pipeline Environmental Conditions

\begin{tabular}{|l|l|}
\hline Pipe Inside Diameter & $3-18 "$ ' $(0.076-0.46 \mathrm{~m})$ \\
\hline Gas Composition & Natural gas $($ mostly methane $)$ \\
\hline Gas Velocity & $10-15 \mathrm{mph}(4.5-6.7 \mathrm{~m} / \mathrm{s})$ \\
\hline Gas pressure & $70-500 \mathrm{psi}(4.7-33 \mathrm{~atm})$ \\
\hline Gas temperature & $5-40 \mathrm{C}$ \\
\hline Natural gas density & $>0.67 \mathrm{~kg} / \mathrm{m}^{3}($ at $20 \mathrm{C}, 1 \mathrm{~atm})$ \\
\hline
\end{tabular}

The power system requirements are given in Table 5-2. Most of the power is consumed during the transmit period, which is quite infrequent (1 sec in 1800s).

Table 5-2. Wireless Sensor System Power and Energy Requirements

\begin{tabular}{|l|l|}
\hline 1. Sensor Power & $0.1 \mathrm{~mW}$ \\
\hline 2. Transmit Power & $75 \mathrm{~mW}$ \\
\hline 3. Transmit duration & $1 \mathrm{sec}$ \\
\hline 4. Message repetition & $1 \mathrm{per} 30 \mathrm{mins}$ \\
\hline 5. Duty cycle, (3)/(4) & $1 / 1800$ \\
\hline 6. Average energy needed, & $4.2 \times 10^{-5}$ watt-hr, $0.15 \mathrm{j}$ \\
\hline 7. Form factor & $1 / 2$ of 2" dia sphere \\
\hline
\end{tabular}

\subsection{Introduction to Wind Turbine Power}

Consider a geometry such as that of Figure 5-1 in which a stream tube of area A goes through a wind turbine. The maximum wind energy available in the environment for harvesting is that which can be extracted from the fluid by an ideal, lossless rotor. The ideal power which can extracted from this stream tube is approximately,

$$
P_{\text {ideal }}=\left(\frac{2}{3}\right)^{3} \rho V^{3} \pi R^{2}
$$

where, $P_{\text {ideal }}$ is the power available in a gas stream of cross-sectional area $\pi R^{2}, \rho$ is the gas density, $\mathrm{V}$ is the gas velocity, and $\mathrm{R}$ is the radius of the stream tube and the wind turbine rotor. 
Figure 5-2 plots this ideal power for a $2 \mathrm{~cm}$ radius wind turbine operating in air at STP and methane at the pipeline conditions given in Table 5-1 which produce the least power. At $4.5 \mathrm{~m} / \mathrm{s}$, there is about $60 \mathrm{~mW}$ of ideal power available in the pipeline stream tube. The actual power that can and must be harvested will be discussed next.

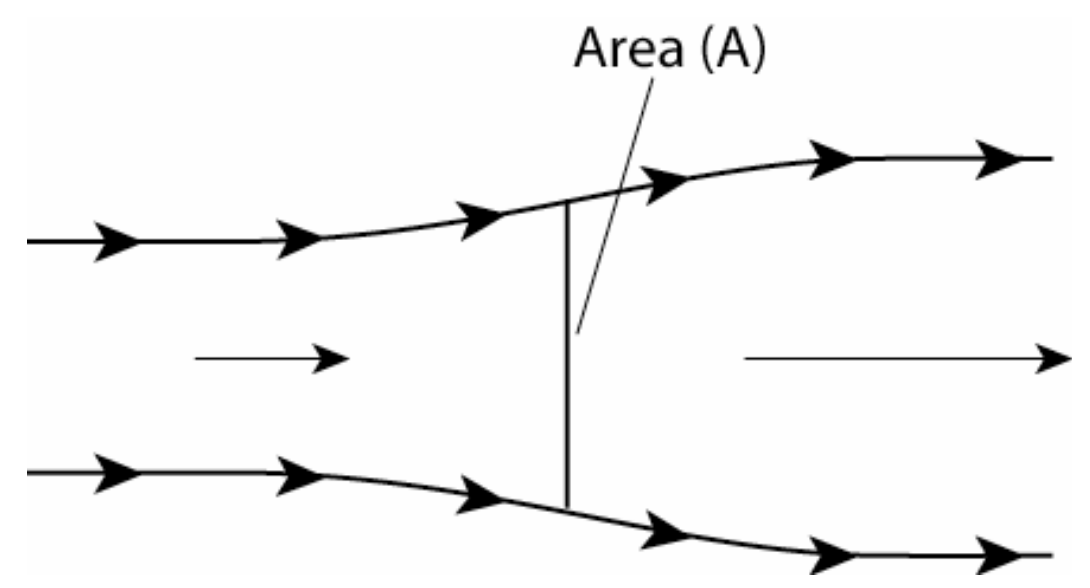

Figure 5-1. Stream tube.

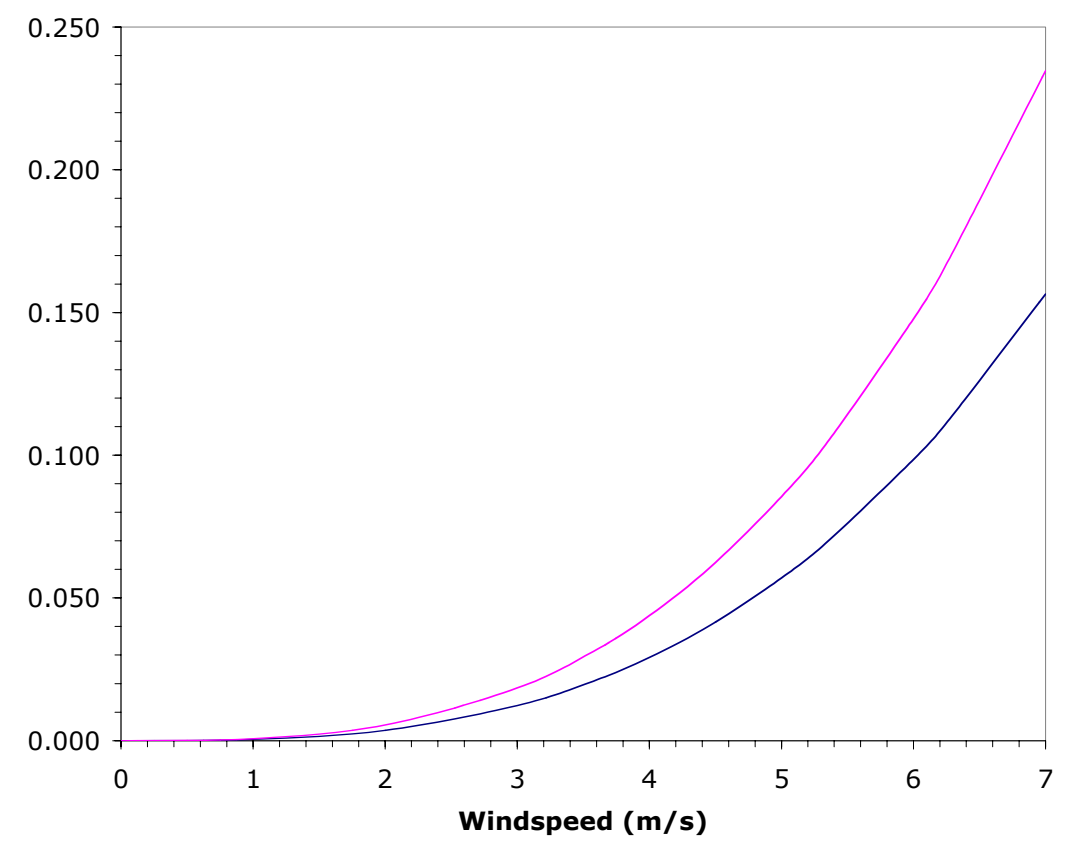

Figure 5-2. Ideal power which can be extracted from a $2 \mathrm{~cm}$ radius gas stream tube.

\subsection{Power System Design}

The power system architecture assumes that the wind turbine will run continuously, charging a battery. The sensor-transceiver will be powered from the battery, both for its high 
power intermittent operation (which consumes most of the energy) and for steady state housekeeping. This simplifies the design and testing of the sensor-transceiver since it only need be designed to operate from a battery.

The functional elements of the power system are illustrated in Figure 5-3. The wind energy is converted to mechanical energy by the wind turbine rotor. This mechanical energy is converted to electrical energy by the generator. The generator controller loads the generator so as to maximize wind turbine life. The battery charger maximizes the charge and life of the battery and prevents overheating. The power conditioner is assumed to be integral with the sensor-transceiver. Note that Figure 5.3 is only a functional diagram. Multiple functions maybe combined into a single circuit element, for example the generator controller and battery charger.

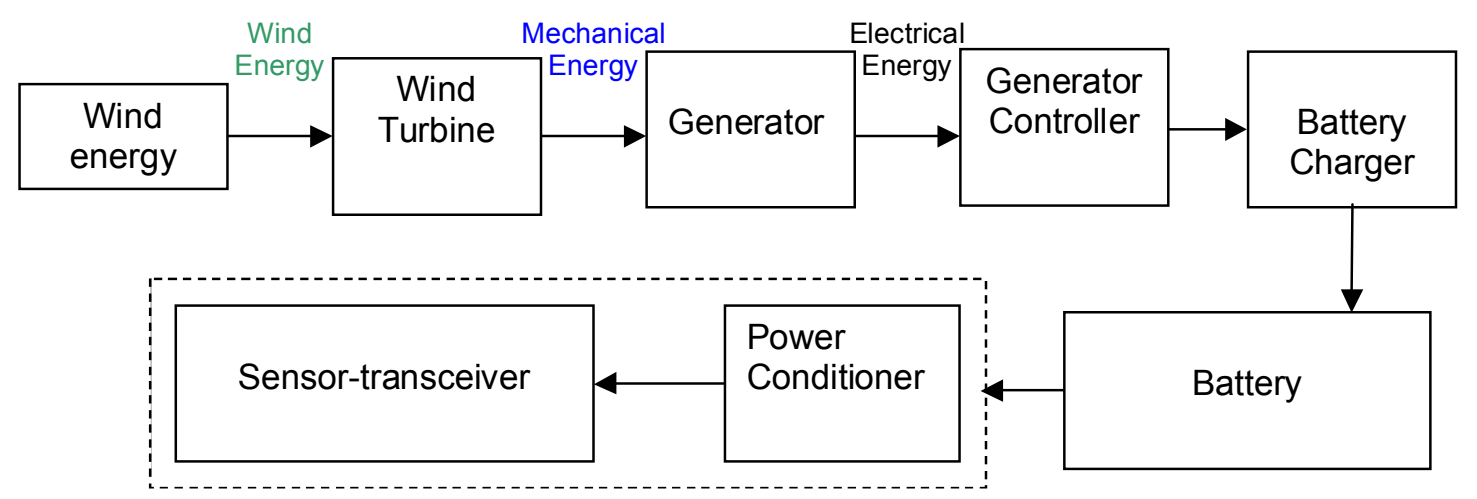

Figure 5-3. Power system architecture.

Power is lost in each element and these losses must be estimated to size the system. The losses are set by a combination of physics, component availability, and design sophistication. Figure 5-4 shows first order estimates of the expected range of component efficiencies $(\eta)$ for each element, assuming a reasonably good design. The net power available to the sensor transceiver is then the ideal power in Figure 5-2 multiplied by the product of these losses, $\eta_{\text {total }}$. In this case, the overall efficiency is $\eta_{\text {total }}=3-13 \%$.

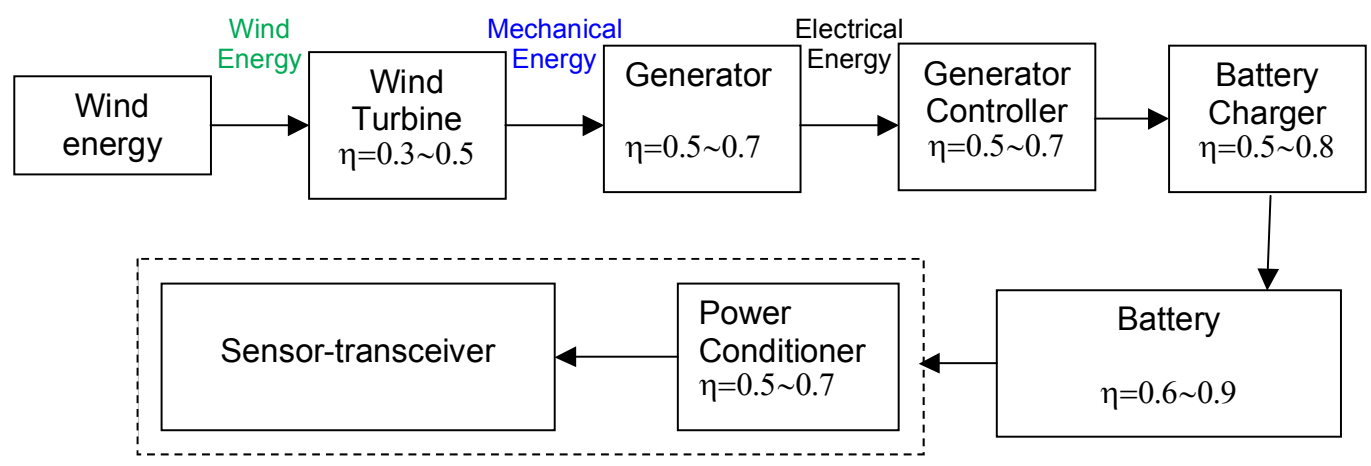

Figure 5-4. Expected range of power system component efficiencies. 


\subsection{Windmill Design}

The windmill consists of a rotor (or propeller) driving a generator. This section briefly explains the design of both components. Rotors and generators have different rpm vs. power vs. efficiency characteristics, so they must be closely matched to maximize power generation.

\subsubsection{Optimum Conversion of Wind to Shaft Power}

A real rotor will extract less power than the theoretical $P_{\text {ideal, }}$ since some power will be consumed by viscous losses, and some power will also be lost to the residual swirl and nonuniform flow behind the rotor. The power which can be extract from this fluid stream is limited by viscous losses in the rotor and residual swirl left in the downstream flow, so at fixed gas velocity, efficiency is a function of rotation speed, rpm. The power which can be extracted by a rotor of optimum geometry in an air flow of $5.4 \mathrm{~m} / \mathrm{s}$ is given in Figure $5-5$ as a function of rotor radius and rpm. Note that this calculation is for rubber rotors, i.e., for a given radius the optimum rotor geometry changes with speed. A fixed geometry rotor will match these curves only at its design point. It is also useful to note that all the curves in Figure 5-5 show less power than predicted by $\mathrm{P}_{\text {ideal }}$. For example, for the $\mathrm{R}=20 \mathrm{~mm}$ rotor, calculation gives $\mathrm{P}_{\text {ideal }}=0.072 \mathrm{~W}$, while the curve in Figure 5-5 shows a maximum $\mathrm{P}=0.038 \mathrm{~W}$ at $6000 \mathrm{RPM}$. So the best possible $20 \mathrm{~mm}$ rotor efficiency is $\mathrm{P} / \mathrm{P}_{\text {ideal }}=0.53$ at $6000 \mathrm{RPM}$.

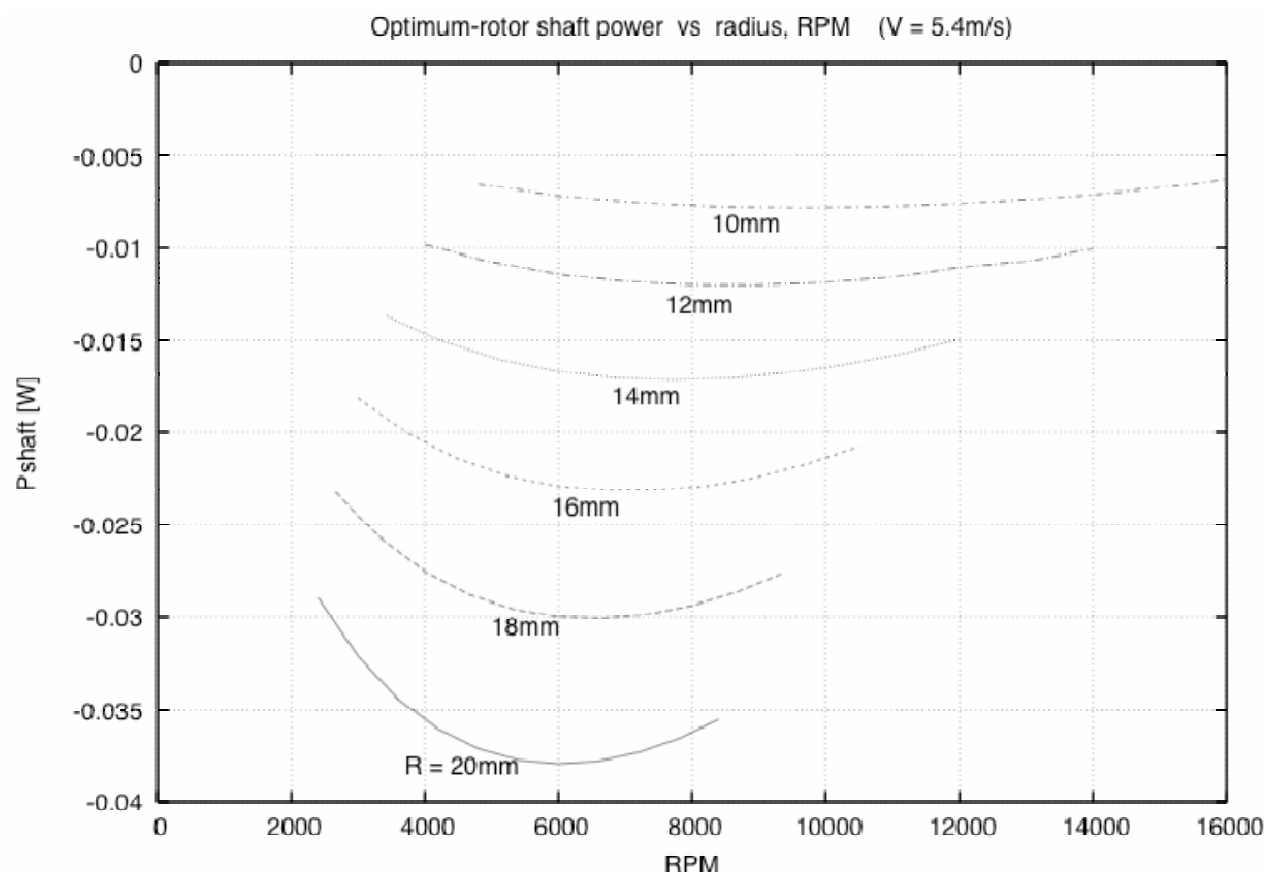

Figure 5-5. Optimum-geometry rotor shaft power as a function of rotor radius for air at $5.4 \mathrm{~m} / \mathrm{s}$ (negative values denote power flowing from the rotor, consistent with propeller theory convention).

This shaft power must then be converted into electricity. Given the project's goals and timeline, we have chosen to design the windmill around a commercially available 
motor/generator. Thus, we will first identify candidate generators, evaluate their suitability with suitable rotor designs, and then select the best generator and rotor.

\subsubsection{Milli-Generator Survey}

We have surveyed commercially available very small motors suitable for use as generators in this application and the most promising found are listed in Table 5-3. All of these motors are large compared to the mechanical shaft power a $20 \mathrm{~mm}$ radius wind turbine can produce, but these are the smallest motors we could identify.

Four of these motors/generators were acquired and tested (3 are shown in Figure 5-6). The choice of test motors/generators was greatly constrained by motor availability (motors of this type may require 10-14 week delivery and large [1000's] orders). The 3-phase motor was not selected because it is more complex to analyze and test and thus beyond the scope of this short project.

Table 5-3. Commercially Available Small Motors

\begin{tabular}{|c|c|c|c|c|c|c|c|}
\hline Manufacturer & Maxon & Maxon & Mabuchi & Mabuchi & Maxon & Faulhaber & Faulhaber \\
\hline Type & RE6 & RE8 & FF-K20WD- & RF-J20WA- & EC-10 & $0615 N$ & 0622K \\
\hline Model Number & 302021 & 261509 & 8127 & $7 Z 75$ & 301999 & $4.5 \mathrm{~S}$ & 012B \\
\hline Nominal Power, W & 0.3 & 0.5 & 0.1 & 0.02 & 0.2 & 0.15 & 1.9 \\
\hline Nominal voltage & 6 & 6 & 1.5 & 1.2 & 5 & 4.5 & 12 \\
\hline No load speed & 21700 & 13900 & 9100 & 21300 & 20100 & 13000 & 42000 \\
\hline Stall Torque, mNm & 0.384 & 0.824 & 0.25 & 0.12 & 0.176 & 0.25 & 1.46 \\
\hline \multicolumn{2}{|l|}{ Stall current, A } & & 0.23 & 0.42 & & & \\
\hline Torque const, $\mathrm{mNm} / \mathrm{A}$ & 2.63 & 3.98 & & & 1.83 & & 2.45 \\
\hline Speed Const, rpm/V & 3840 & 2400 & & & 5220 & 4,727 & 3900 \\
\hline Speed/torque, rpm/mNm & 58100 & 17500 & & & 149000 & & 31500 \\
\hline Max eff, \% & 59 & 67 & 35 & 24 & 30 & 50 & 50 \\
\hline Max axial bearing load, $\mathrm{N}$ & 0.15 & 0.15 & & & 1 & & 1 \\
\hline Overall length, mm & 22.9 & 25.7 & 20.5 & 17.4 & 6.1 & 23 & 27 \\
\hline Motor Diameter, $\mathrm{mm}$ & 6 & 8 & 8 & 6 & 9.9 & 6 & 6 \\
\hline Shaft length, dia, $\mathrm{mm}$ & $2,0.83$ & $3.5,0.8$ & $4.5,1.0$ & $5.2,1.0$ & $1,1.25$ & & 1.75 \\
\hline Weight, g & 2.3 & 4.1 & 2.4 & 1.3 & 0.85 & 0.07 & 3.3 \\
\hline Max Temp, C & 85 & 85 & & & 85 & 85 & 85 \\
\hline Bearing type & Sleeve & Sleeve & Sleeve & Sleeve & Ball & Sleeve & Ball \\
\hline Motor type & $\mathrm{DC}$ & $\mathrm{DC}$ & DC-PM & DC-PM 3 & 3 phase $A C$ & DC coreless & 3 phase $A C$ \\
\hline
\end{tabular}




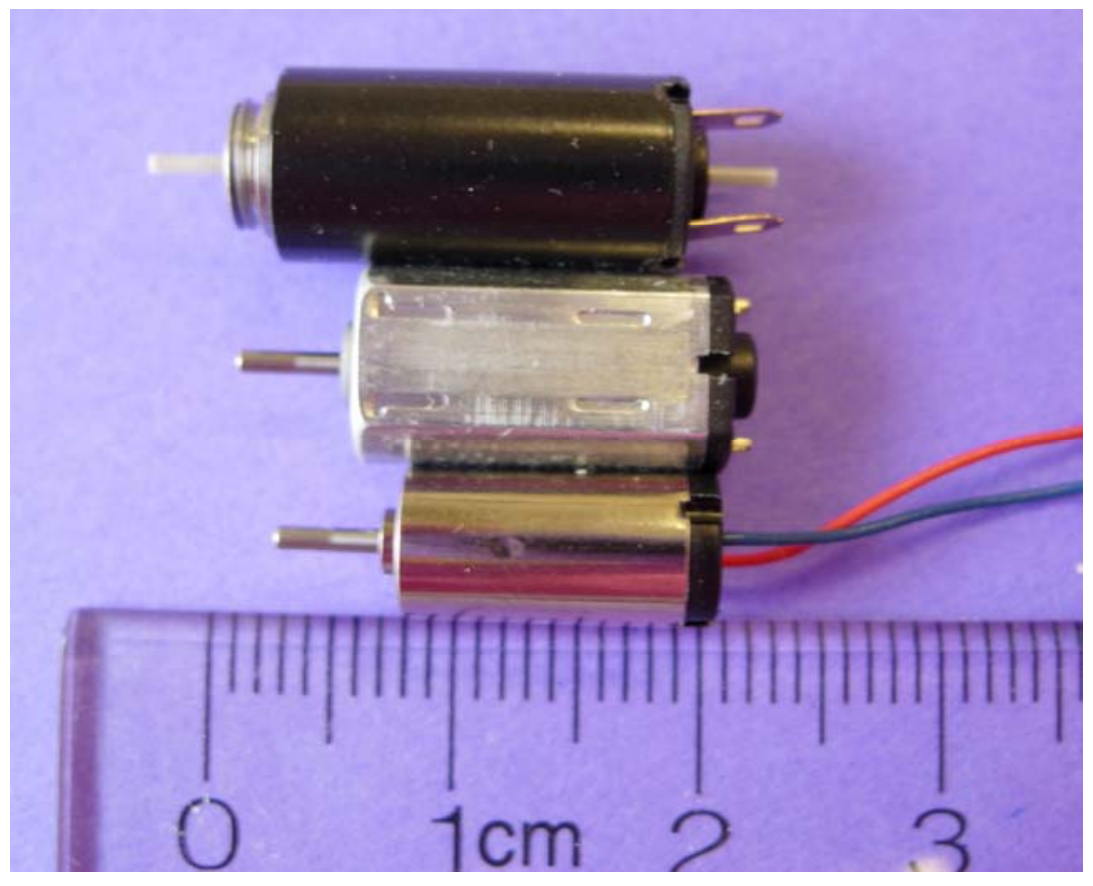

Figure 5-6. Motors tested (top to bottom): Maxon RE8, Mabuchi 8127, Mabuchi $7 Z 75$.

\subsubsection{Motor Modeling}

The characteristics of a brushed DC motor/generator can be fairly accurately predicted by knowing the following three readily-measured motor constants:

$R$ motor resistance

$i_{O} \quad$ motor zero-load current

$K_{v}$ motor speed constant

The manufactures' values are given in Table 5-3, but since there can be substantial variations among very small motors, these values were verified experimentally as well. The motor/generator torque and efficiency are then estimated rather well by the following function of the rotation rate $\Omega$ and terminal voltage $v$.

$$
\begin{gathered}
Q_{m}(\Omega, v)=\left[\left(v-\frac{\Omega}{K_{v}}\right) \frac{1}{R}-i_{o}\right] \frac{1}{K_{v}} \\
\eta_{m}(\Omega, v)=\left[1-\frac{i_{o} R}{v-\Omega / K_{v}}\right] \frac{\Omega}{v K_{v}}
\end{gathered}
$$

The data from the motor/generator tests were used to formulate a simple model of each unit which predicts the generator voltage, power, and efficiency as a function of speed and load. These models were then combined with that of the optimal rotor to yield a prediction of the maximum power that could be generated by an optimal geometry rotor as a function of rotor 
radius and output voltage (for these generators, voltage scales with rpm). These results are shown in Figures 5-7 and 5-8. The smallest dc motor/generator available, the Mabuchi 7Z75, is wound for low voltage and thus will produce less than $0.8 \mathrm{~V}$ at $5 \mathrm{~mW}$ and $0.5 \mathrm{~V}$ at $12 \mathrm{~mW}$ as can be seen in Figure 5-7.

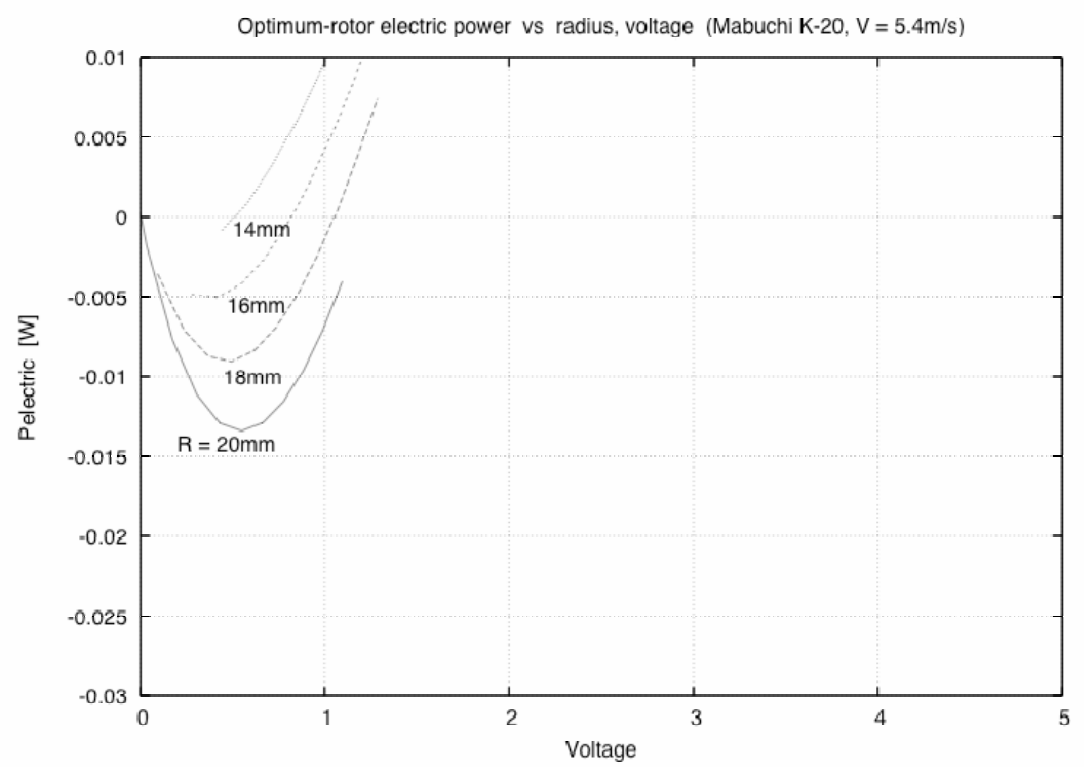

Figure 5-7. Predicted output for an optimal rotor driving at Mabuchi $\mathbf{7 Z 7 5}$ motor/generator at a gas velocity of $5.4 \mathrm{~m} / \mathrm{s}$

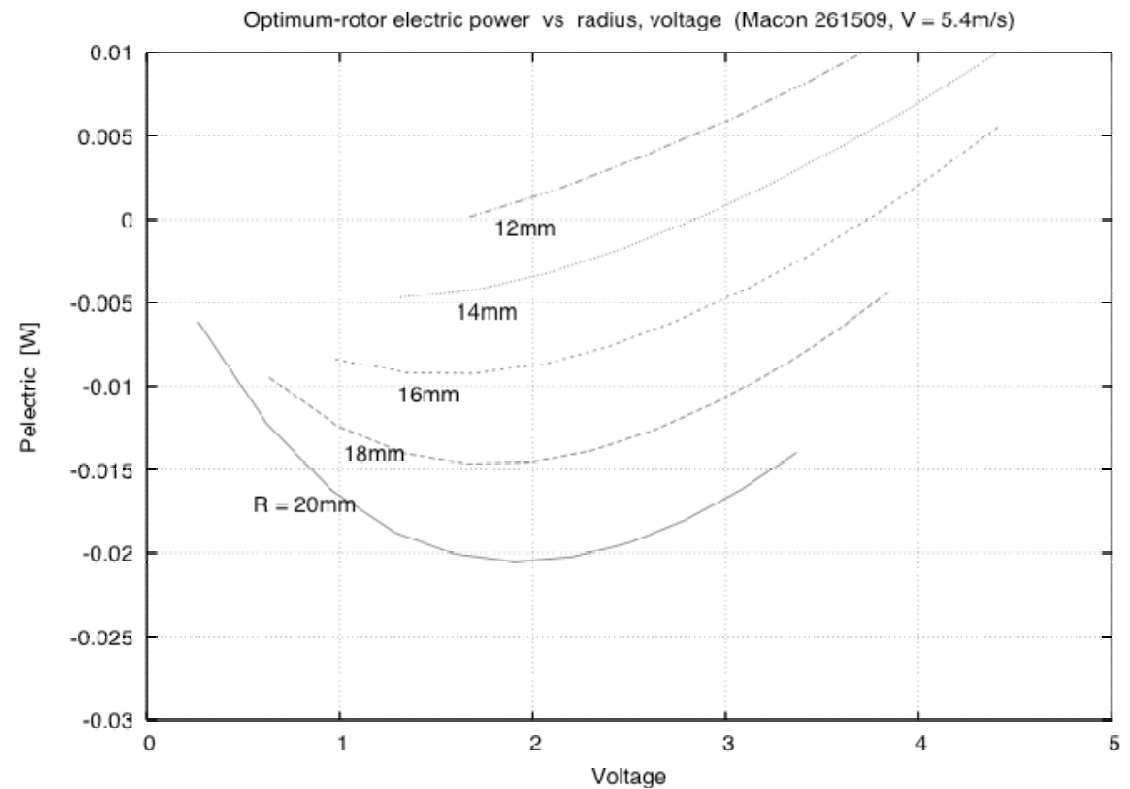

Figure 5-8. Predicted output for an optimal rotor driving a Maxon RE8 261509 motor/generator at a gas velocity of $5.4 \mathrm{~m} / \mathrm{s}$. 
The Maxon RE8 261509 can produce about 2V at $20 \mathrm{~mW}$ under similar conditions and up to perhaps $3 \mathrm{~V}$ at $5-10 \mathrm{~mW}$ as can be seen in Figure 5-8. These higher voltages are much better suited to battery charging than are the Mabuchi outputs.

\subsubsection{Rotor Modeling}

Calculation of the windmill rotor torque and efficiency is far more complicated than that of the generator. The present approach is very similar to the classical propeller analysis method of Larrabee and French ${ }^{1}$ enhanced with extensions to improve accuracy at large disk loadings. This analysis requires knowing the profile drag on the blade airfoils, which is computed using the XFOIL $\operatorname{code}^{2}$. It is sufficient to state here that the method predicts the rotor torque and efficiency as functions of the rotation rate and wind speed.

$$
\begin{gathered}
Q_{p}=Q_{p}(\Omega, V) \\
\eta_{p}=\eta_{p}(\Omega, V)
\end{gathered}
$$

The shaft power is then simply

$$
P_{\text {shaft }}(\Omega, V)=Q_{p} \Omega
$$

\subsubsection{Rotor Design Objective}

It is useful to first consider some basic limits on the performance obtainable from a windmill. According to actuator disk theory, the ideal power which can possibly be delivered by a windmill rotor is

$$
P_{\text {ideal }}=\frac{8}{27} \rho V^{3} \pi R^{2}
$$

which is known as the Betz Limit. In practice, the actual shaft power will be less than this because of inefficiencies due to friction drag on the blades, nonzero swirl downstream of the rotor, and tip losses from a finite number of blades.

$$
P_{\text {shaft }}=\eta_{p} P_{\text {ideal }}
$$

The electrical power will in turn be less than the shaft power because of the motor/generator efficiency.

$$
P_{\text {electric }}=\eta_{m} P_{\text {shaft }}=\eta_{m} \eta_{p} P_{\text {ideal }}
$$

Given some wind speed, maximum rotor diameter, and motor characteristics, the design objective is to determine the windmill rotor geometry and operating RPM so that $P_{\text {electric }}$ is maximized. Or equivalently, the overall generating system efficiency

$$
\eta=\eta_{m} \eta_{p}
$$


is to be maximized. The design procedure is somewhat similar to the classical design approach of Larrabee and French, with extensions for large disk loadings. The design output is the blade geometry, in the form of radial chord and blade angle distributions.

\subsubsection{Integrated Design Considerations}

The motor and rotor efficiencies $\eta_{m}$ and $\eta_{p}$ will in general vary with rotation rate. If a gearbox is not used, it is important that these two peaks occur at roughly the same rotation speeds $\Omega$, so that the motor and rotor are well matched. For very small motors and windmills, these efficiency peaks occur at roughly the following conditions:

At $\eta_{m}$ peak: $\Omega \cong 1.5 v K_{v}$

At $\eta_{p}$ peak: $\Omega \cong 2.5 V / R$

Hence, the approximate rotor/motor speed-matching requirement is

$$
v K_{V} \cong 1.67 \mathrm{~V} / R
$$

If $V$ and $R$ are set by the available windspeed and required power, then any desired output voltage requires selection of a specific motor $K_{v}$, or vice versa.

\subsubsection{Rotor Analysis}

Once a motor is chosen and rotor geometry designed for some specified wind speed $V$ and motor load parameters $\Omega$ and $v$, it is desirable to determine the off-design performance for the rotor/motor combination for a range of wind speeds and applied voltages. This is done by combining the motor equations and the rotor analysis results with the constraint that the motor and rotor torques are equal.

$$
\begin{gathered}
V=V_{1}, V_{2}, V_{3} \cdots \\
v=v_{1}, v_{2}, v_{3} \ldots \\
Q_{m}(\Omega, v)=Q_{p}(\Omega, V)
\end{gathered}
$$

The result is a predicted rotational speed, $\Omega$, and corresponding motor current, $i$, and electrical power $P_{\text {electric }}=v i$ for each $V, v$ combination.

$$
V, v \rightarrow \Omega, i, P_{\text {electric }}
$$

The last design consideration is the axial thrust produced by the rotor, which must be carried by the motor's bearings. This is axial force is approximately $0.01 \mathrm{~N}$ at $5 \mathrm{~m} / \mathrm{s}$ and scales with $V^{2}$, which is well within the $0.15 \mathrm{~N}$ rated capability of the smallest motor listed in Table 5-3. 


\subsection{Verification and Discussion for Mini-Windmill}

\subsubsection{Rotor Geometry}

A $2 \mathrm{~cm}$ radius micro wind turbine was designed to match the Maxon $261509 \mathrm{dc}$ motor/generator at $5.4 \mathrm{~m} / \mathrm{s}$ using the procedure outlined above. The $2 \mathrm{~cm}$ radius was chosen to consistent with the windmill occupying no more than $1 / 2$ of a 2 inch diameter sphere. This rotor design was constructed of glass-epoxy. Each blade was formed in a numerically machined mould and then the blades were joined at the hub to complete the rotor. The rotor was then mated to either the $6 \mathrm{~mm}$ or 8mm diameter Maxon motors (RE6-302021, RE8-261509). The complete milli wind-turbine consisting of the $2 \mathrm{~cm}$ radius rotor on the Maxon RE6 motor is shown in the photos in Figure 5-9. The motor is inserted in an aluminum tube which serves as the support for wind tunnel testing.

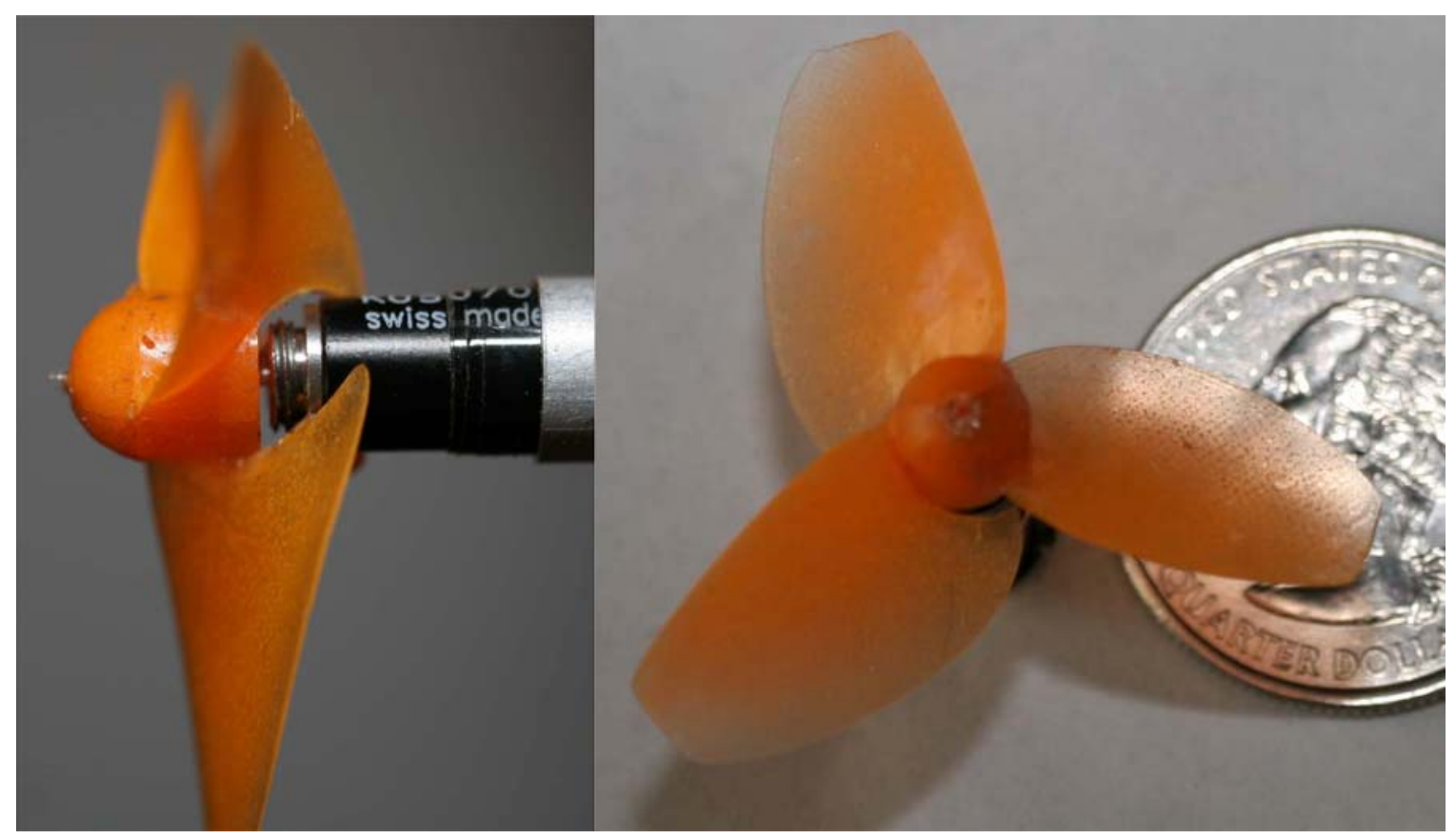

Figure 5-9. Photo of $2 \mathrm{~cm}$ radius rotor on Maxon RE6 motor/generator.

The $2 \mathrm{~cm}$ radius rotors were tested on both the RE6 and RE8 Maxon motors at wind speeds ranging from $8-14 \mathrm{mph}$ in a 1 foot square wind tunnel. Each motor had its own rotor, although both were constructed from the same molds. A reference anemometer measured the airspeed. At each airspeed, the resistive load on the generator was varied and the resultant voltage and current measured with digital multimeters.

As is the usual practice, negative current and power denotes power flowing from the motor/generator, i.e., power generation. For each wind speed, the data are plotted in terms of amps versus volts and output power (volts times amps) versus volts. For dc motors such as these, the output voltage is nearly proportional to the rotation rate so that the horizontal axis could also be plotted in terms of rpm (although the rpm was not directly measured). 
The data and predictions agree well for both motors, quite well for the RE6 motor. Above $0.5 \mathrm{~V}$, the current versus voltage characteristic are linear at all wind speeds. At voltages and low wind speed, airflow begins to separate from the rotor blades so the torque and thus current drop in the data. The predictions do not exhibit this trend because they do not include a accurate model of stalling airfoil behavior (which would require a more sophisticated level of modeling). The generator efficiency generally peaks at about $1 / 7$ the stall torque while power output is a maximum at $1 / 2$ the stall torque.

The data and predictions do not agree as well for the larger RE8 motor as the did for the RE6. Above $1.0 \mathrm{~V}$, the current versus voltage characteristic are linear at all wind speeds. At higher currents, the larger motor overloads the rotor, stalling the airfoils, behavior not well captured in the simple models used.

In general, the smaller RE6 motor produces more power at lower voltages and therefore $\mathrm{rpm}$. However, we are mostly interested in reducing power at the higher voltages, conditions under which larger RE8 motor generates more power. Since the effective load a battery places on the generator is a function of the battery charge state, it is evident that a battery charging circuit which modulates the generator load to keep voltage (rpm) high over a variety of wind speeds can maximize useful power produced. The overall efficiency increases with airspeed, ranging from $21-26 \%$ for the RE6 and $15-33 \%$ for the RE8.

The test results show that is indeed possible to generate sufficient power from a windturbine consistent with a required size and form factor. This section briefly discusses application related issues such as scaling, battery charging, and service life.

\subsubsection{Wind-tunnel Demonstration}

The small wind-turbine was demonstrated at MIT laboratories in air. In the least favorable of pipeline conditions ( $3 \mathrm{~atm}$ at $40 \mathrm{C}$ ), it should produce about $50 \%$ more power than in the atmospheric air tests. A wireless sensor requires about $0.3-0.4 \mathrm{~mW}$ at the generator output while this wind-turbine can produce 10-100 times that. As such, the demonstrated wind-turbine can be considered oversized for this application. Conceptually, the unit can be downsized or the excess power capacity used to add functionality to the sensor, range-bandwidth to the transceiver, or permit less costly circuit implementations (battery charging, power converter, etc.).

While the rotor area can be readily reduced, we are unaware of any smaller (in particular, shorter) dc motors that are suitable for this application (the Mabuchi motors are wound to too low a voltage and have poor efficiency). It appears that the size can be reduced, however, if an ac flat motor is used such as the Maxon EC-10 listed in table 5.3. The flat motor is less than 7 $\mathrm{mm}$ long compared to the 23-27 mm length of the dc motors. A multi-phase ac motor/generator would require more a complex battery charging circuit than is needed for a dc generator.

DC motors can be directly connected to batteries. While perhaps the simplest approach to battery charging, this is not the most efficient, fastest, or safest. In the case of the windmill, a diode must be inserted between the generator and battery to prevent the battery motoring the 
windmill when the wind speed is low. Several battery charging "power management" chips are available to maximize battery charging and safety.

The motors tested were both designed for 6 volt operation. The test results indicated that these motors are well suited to charging $1.5 \mathrm{~V}$ batteries. If higher voltages are needed, the RE8 motor can be special ordered with $12 \mathrm{~V}$ windings (model 261510). Extrapolating the results from the tests of the 6 volt version (261509) to the 12 volt model the optimum-rotor powered generator could produce $10-15 \mathrm{~mW}$ at $3-5 \mathrm{~V}$. This is adequate voltage to charge $3 \mathrm{~V}$ batteries with a series diode. Charging batteries from voltage sources lower than the battery needs is possible, but requires more complex and sophisticated circuits, which are beyond the scope of the current effort.

Another factor to consider is the windmill life, especially in the harsh environment of a gas pipeline. The rotor life will be limited by erosion which would be maximized by replacing the glass epoxy of the test articles with steel. The generator life will be set by the bearing and brush life. One approach to maximizing life would be to use an ac motor-generator such as the Maxon EC-10 which uses ball bearings rather than the sleeve bearings of the small dc motors, and has no bearings to wear. The main constraint to size reduction is the availability of suitable small generators. Changing from a dc to ac generator may permit a factor of two reductions in size at the cost of charging circuit complexity. 


\subsection{SENSOR MOTION AND DELIVERY TO LOCATIONS OF INTEREST}

Fluid dynamics modeling has been used to explore the effects of size and weight on the fluidic properties of the potential motes sensors. The initial modeling effort was aimed at calculating the pipe inclination angle where a spherical probe of a varying size and density will start to move up the inclination because the gas flow overcomes the gravitational forces or stall. Since it was assumed that the probes would be inserted into flowing pipelines, the force required to overcome friction was been neglected. The force balance is shown schematically in Figure 6-1.

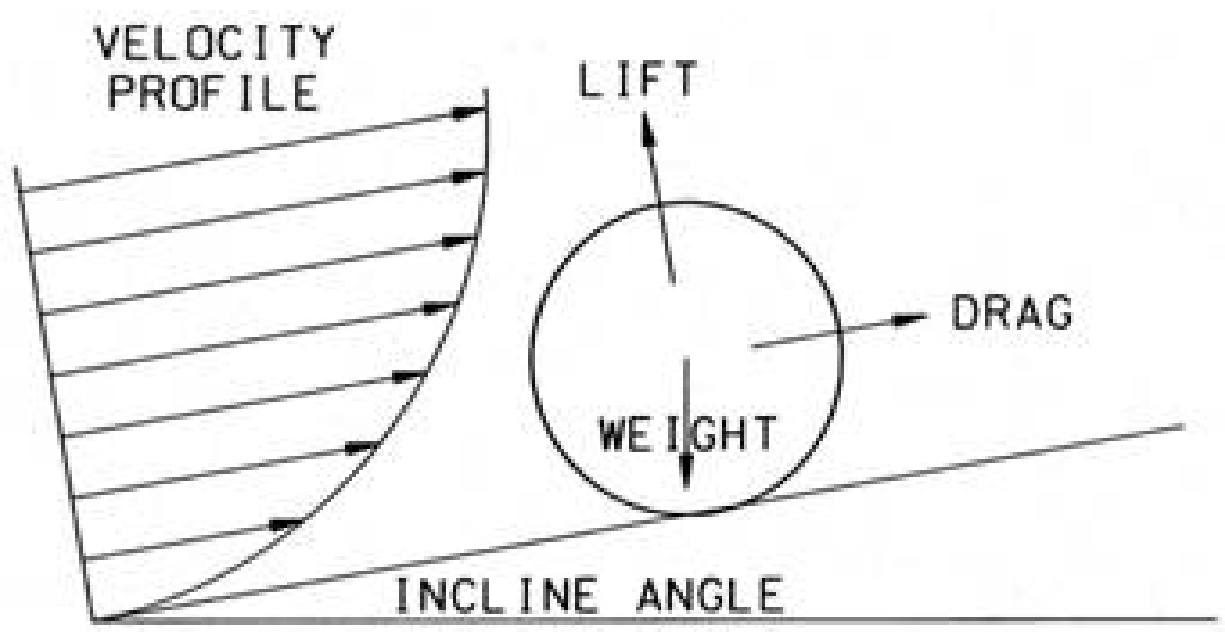

Figure 6-1. Schematic of force balance for spherical sensors moving inside a pipeline.

The approach is essentially identical to that used for ICDA. The model has been used to predict the inclination angle for a variety of different flowing conditions. Figure 6-2 shows the results for a probe of varying density (weight), 1.5 in diameter, flowing in an 8 in Schedule 80 pipeline at 800 psi. At velocities lower than the computed value, the probe will not travel up the given inline. The model indicates that a velocity of approximately $7.5 \mathrm{ft} / \mathrm{s}$ is required to move a 1.5 in diameter probe $(0.5 \mathrm{~g} / \mathrm{cc}$ density $)$ up an incline of $10^{\circ}$. A velocity of approximately $19 \mathrm{ft} / \mathrm{s}$ is required to move a 1.5 in diameter probe $(3 \mathrm{~g} / \mathrm{cc}$ density) up an incline of $10^{\circ}$. The velocity required to move the $3 \mathrm{~g} / \mathrm{cc}$ probe is more than 2.5 times the velocity required to move the $0.5 \mathrm{~g} / \mathrm{cc}$ probe up the same incline.

The model was then used to explore other variables including sensor size and pipeline operating pressure. Figure 6-3 shows the results for a probe of varying density, 1.0 in diameter, flowing in an 8 in Schedule 80 pipeline at 800 psi. The model indicates that a velocity of approximately $6.5 \mathrm{ft} / \mathrm{sec}$ is required to move a 1.0 in diameter probe $(0.5 \mathrm{~g} / \mathrm{cc}$ density) up an incline of $10^{\circ}$ compared to the $7.5 \mathrm{ft} / \mathrm{s}$ required for a 1.5 in diameter sensor. When the sensor size is reduced to 0.5 in diameter (Figure 6-4), only $5 \mathrm{ft} / \mathrm{s}$ is required to move up a 10 (again using the $0.5 \mathrm{~g} / \mathrm{cc}$ density). Calculations also showed that the operating pressure of the pipeline had a significant influence on the required velocity for a sensor to climb an incline. The effect of pressure on the required velocity for a 1.0 -inch diameter probe $(2 \mathrm{~g} / \mathrm{cc}$ density) is shown in 
Figure 6-5. At 1,400 psi, a velocity of approximately $10 \mathrm{ft} / \mathrm{sec}$ is required to move a 1.0 -inch diameter probe $(2 \mathrm{~g} / \mathrm{cc})$ up a $10^{\circ}$ incline. At $200 \mathrm{psi}$, a velocity of $27 \mathrm{ft} / \mathrm{sec}$ is required to move the same probe up the same incline.

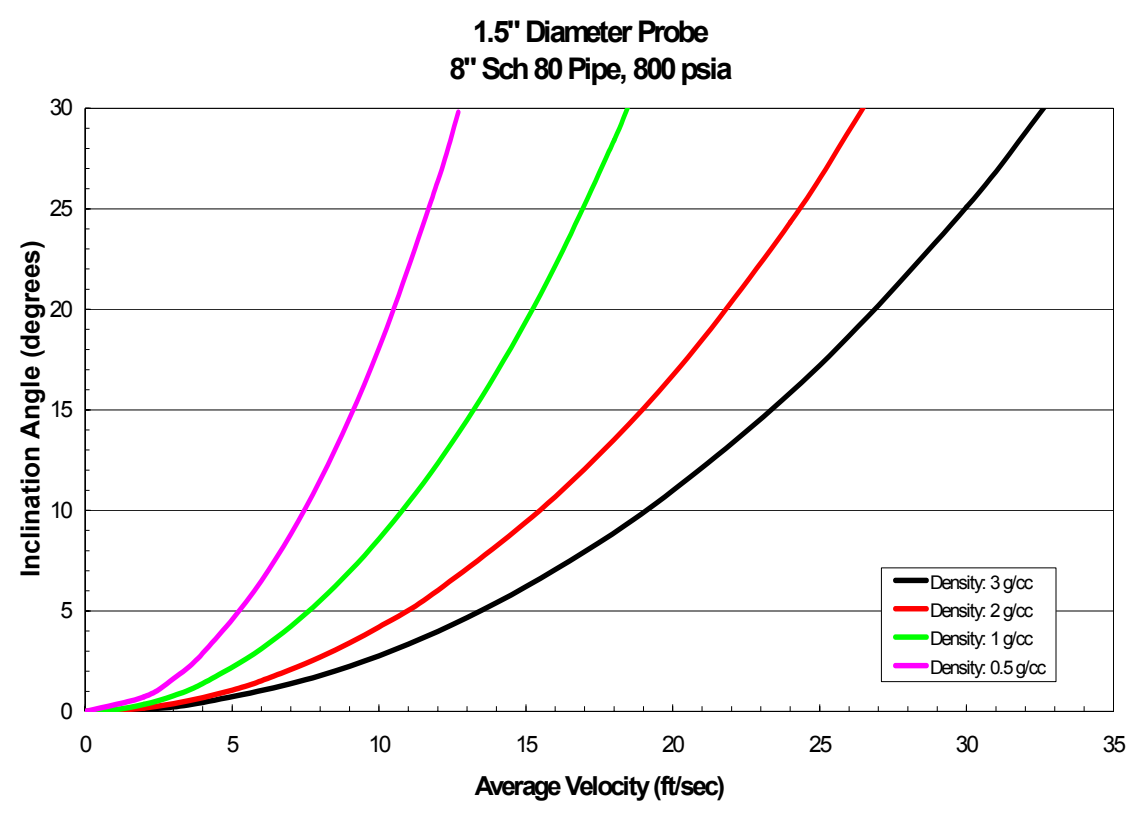

Figure 6-2. Critical incline angles that can be climbed as a function of gas velocity for a $\mathbf{1 . 5}$ inch probe with different densities.

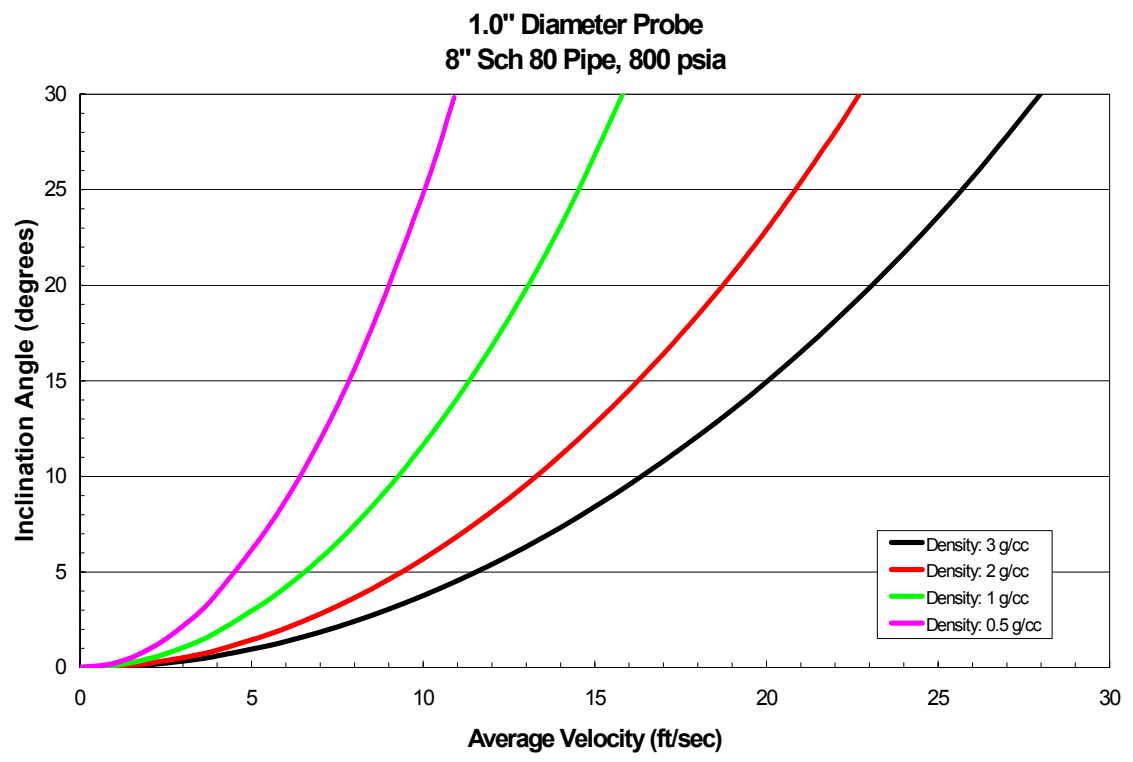

Figure 6-3. Critical incline angles that can be climbed as a function of gas velocity for a 1.0 inch probe with different densities. 


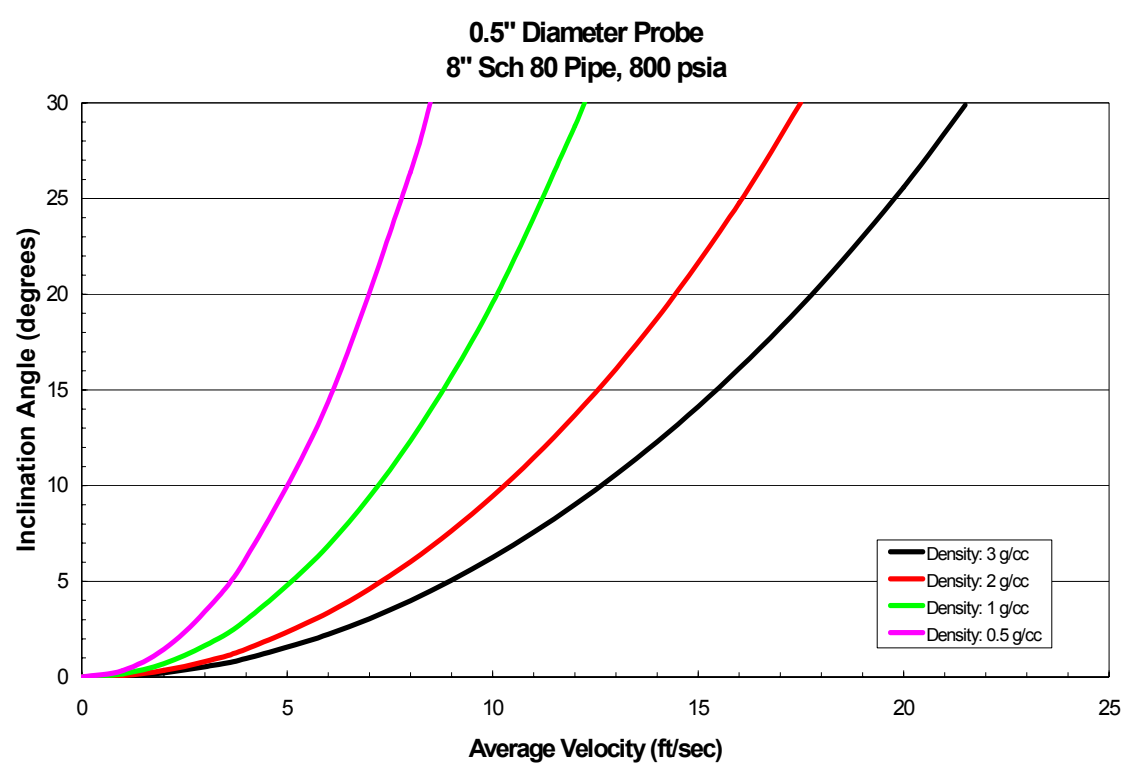

Figure 6-4. Critical incline angles that can be climbed as a function of gas velocity for a 0.5 inch probe with different densities.

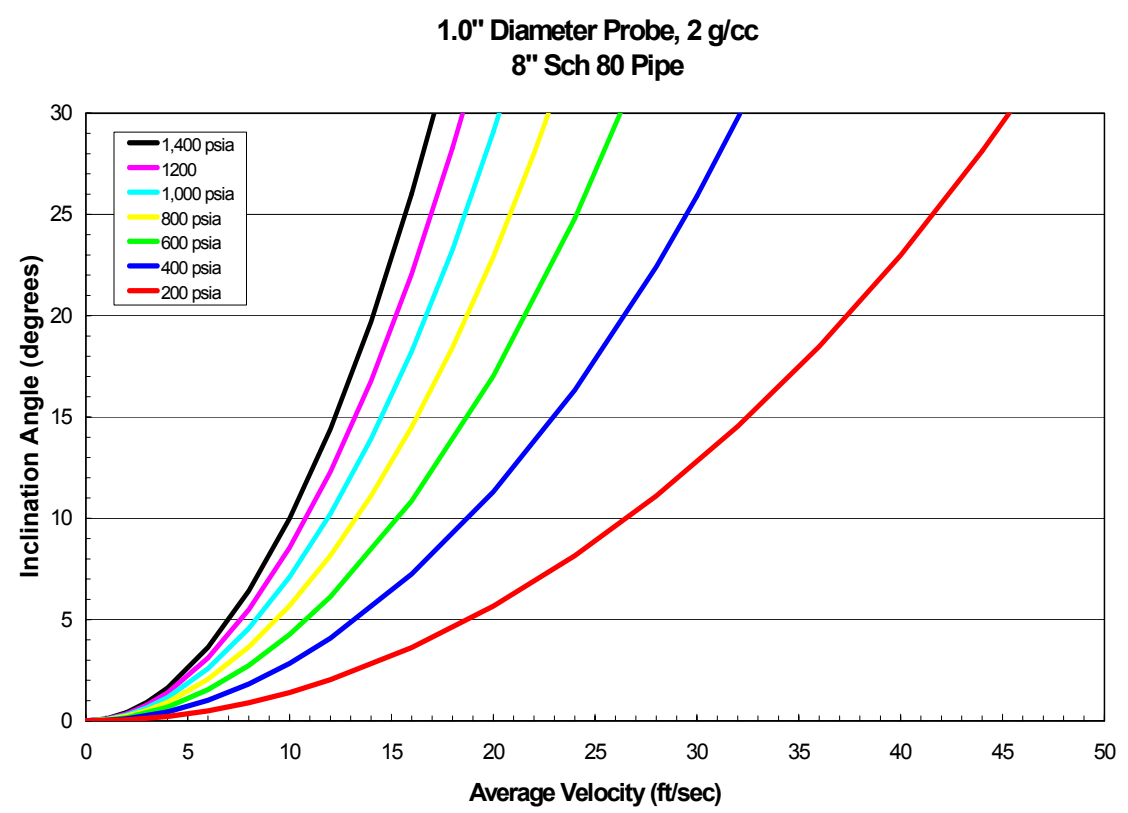

Figure 6-5. Critical incline angles that can be climbed as a function of gas velocity for a 1.0 inch probe at different pipeline operating pressures. 


\subsection{SUMMARY AND RECOMMENDATIONS}

The overall objective of the proposed project is to enable remote interrogation of possible internal corrosion of pipelines by establishing a distributed wireless sensor network inside the pipe using miniaturized sensor packages introduced into the gas stream. To accomplish this, the project is divided into four main tasks related to wireless data transmission, corrosion sensor development, sensor system motion and delivery, and consideration of other pipeline operations issues. In the first year of the program, focus was on sensor development and wireless data transmission. The second year of the program, which was discontinued due to funding shortfall, would have focused on further wireless transmission development, packaging of sensor on wireless, and other operational issues. Because, the second year funding has been discontinued, recommendations are made for future studies.

\subsection{Wireless Transmission}

Transmission along distances within a pipe was shown to be feasible, and more efficient within the pipeline than for open-air transmissions. Communication from within the pipe to an external receiver occurs at any gap in metallic continuity in the pipe (e.g., non-metallic discontinuities are provided to prevent long-line telluric currents). Alternatively, locations of corrosion coupon in pipeline can be used to extract signals from within the pipe. Communicating the location of the sensor from within the pipe is still a challenge. Ultra Wide Band transmission does not appear to penetrate the pipe consistently. Low frequency signal (e.g., AM radio type signal) can penetrate steel and ground cover. A scheme for using low frequency signal is suggested in this report, but has not been tested. Once again, the possibility of using internal corrosion coupon a communication path should be explored.

\subsection{Sensor Design}

Several sensor platforms were evaluated for use as corrosion sensors on a wireless platform. The electrical resistance probe was not shown to be sensitive enough for use as a fluidized sensor, although situations involving long-term exposure measurements may be suitable for such a probe. The interdigitated galvanic couple sensor made of silver-graphite couple was successful at quickly determining general environmental corrosivity, but not actual corrosion rates. The multielectrode array sensor (MAS) probe, which has been shown in previous work to yield real-time corrosion rates, was successfully adapted to the fluidized sensor platform as a miniaturized version of the traditional probe and/or as a thin-film flexible circuit sensor (TMAS). The combination of these sensors would satisfy the requirements set forth for design of a fluidized corrosion sensor. A sensor and electronics system based on MAS has yet to be built.

\subsection{Sensor Power Needs}

Battery power, while a readily available solution is not a long-term solution. One method of actively powering the sensor is to harvest the energy of moving gas to charge a battery. Several wind mill concepts using small motors were examined. A theoretical analysis indicated that wind driven power transformation is possible. Limited wind tunnel testing showed that 
wind velocity typical of that expected in a pipeline can generate adequate power for charging the battery. The design of such a power system has to be completed.

\subsection{Sensor Flow Characteristics}

The effect of gas velocity, sensor density, and pipeline inclination angle on the ability of sensor to move or deposit at a given location was analyzed. The calculations provided a method to develop sensor parameters to enable deposition at a location of water hold-up.

\subsection{Recommended Future Activities}

Further evaluation of the method to locate the sensor along the pipeline is necessary. Although location using low frequency signal is possible, this needs demonstration. Alternative location methods must be explored.

The sensor and wireless device should be packaged and the assembly should be tested in a pipeline prior to validation in the field

The durability of the sensor and package should be assessed and, if necessary, improved

The long-term powering of the package should be further explored. Power generation using the gas flow appears to be feasible, but further development of the equipment and demonstration is necessary.

The impact of the sensor package on the operation of pipeline should be assessed. 


\subsection{REFERENCES}

D. Burwell, N. Sridhar, O.C. Moghissi, and L. Perry, Internal Corrosion Direct Assessment Of Dry Gas Transmission Pipelines - Validation, CORROSION/2004 paper \#04195, NACE International, Houston, TX, (2004).

Drela, "XFOIL: An Analysis and Design System for Low Reynolds Number Airfoils", SpringerVerlag Lecture Notes in Engineering, No. 54, 1989. Also: http://raphael.mit.edu/xfoil.

A. Kale, B.H. Thacker, N. Sridhar, and C. Waldhart, A Probabilistic Model for Internal Corrosion of Gas Pipelines, IPC04-0483, International Pipeline Conference, Calgary, Canada, ASME, (2004).

Larrabee and French, "Minimum Induced Loss Windmills and Propellers", Journal of Wind Engineering and Industrial Aerodynamics, Vol. 15, 1983.

O. Moghissi, L. Norris, P. Dusek, and B. Cookingham, Internal Corrosion Direct Assessment of Gas Transmission Pipelines, Paper No. 02087, Corrosion/2002, NACE International, Houston, TX, (2002).

O.C. Moghissi, L. Perry, B. Cookingham, and N. Sridhar, 'Internal Corrosion Direct Assessment of Gas Transmission Pipelines - Application,' CORROSION/2003 paper \#03204, NACE International, Houston, TX, (2003). 